\title{
A META-ANALYSIS OF WORK DEMAND STRESSORS AND JOB PERFORMANCE: EXAMINING MAIN AND MODERATING EFFECTS
}

\author{
SIMONA GILBOA AND ARIE SHIROM \\ Faculty of Management \\ Tel Aviv University \\ YITZHAK FRIED \\ Whitman School of Management \\ Syracuse University \\ CARY COOPER \\ University of Lancaster
}

\begin{abstract}
We quantitatively integrated 169 samples ( $N=35,265$ employees) that have been used to investigate the relationships of the following 7 workrelated stressors with job performance: role ambiguity, role conflict, role overload, job insecurity, work-family conflict, environmental uncertainty, and situational constraints. Overall, we obtained a negative mean correlation between each job performance measure and each stressor included in our analyses. As hypothesized, role ambiguity and situational constraints were most strongly negatively related to performance, relative to the other work-related stressors. Analysis of moderators revealed that (a) the negative correlation of role overload and performance was higher among managers relative to nonmanagers; (b) publication year moderated the relation of role ambiguity and role overload with performance, although in opposite directions; (c) the correlations obtained for published versus unpublished studies were not significantly different; and (d) using the Rizzo et al. scale of role ambiguity and role conflict decreased the magnitude of the correlations of these stressors with performance, relative to other scales. Theoretical contributions, future research directions, and practical implications are discussed.
\end{abstract}

Psychosocial stressors at work represent a ubiquitous and multifaceted phenomenon (Lazarus, 1993); several theoretical frameworks predict that they affect employee attitudes and behaviors (Jex \& Crossley, 2005). Most past meta-analytical reviews of these relationships focused only on the linkages of role conflict and role ambiguity with job performance, none of

This paper was accepted under the editorship of Ann Marie Ryan.

We gratefully acknowledge the financial support for this study from the Henry Crown Institute of Business Research in Israel, Faculty of Management, Tel Aviv University.

Correspondence and requests for reprints should be addressed to Arie Shirom, Faculty of Management, Tel Aviv University, P.O. Box 39010, Tel Aviv 69978, Israel; ashirom@post.tau.ac.il. 
them related to unpublished studies, and each included only a relatively small number of samples, casting doubt on their findings regarding the effect of possible moderators (e.g., Abramis, 1994, $n=18$ for role ambiguity only; Fisher \& Gitelson, 1983, $n=25,22$; Jackson \& Schuler, 1985, $n=37$, 24; Tubre \& Collins, 2000, $n=74,54$ for the meta correlations of performance with role ambiguity and role conflict, respectively). All previous meta-analytical reviews found that a substantial amount of the variance in the corrected stressor-performance correlations remained unexplained and urged future researchers to identify variables that moderate this relationship (e.g., Tubre \& Collins, 2000, p. 166).

We have advanced and refined this knowledge concerning the relationships between stressors and job performance in three major ways. First, in addition to role ambiguity and role conflict, we have included role overload, job insecurity, work-family conflict, and situational constraints, four stressors that have been covered to only a limited extent by prior metaanalytical studies, and environmental uncertainty, which has not been examined in relation to job performance in any previous quantitative review. All seven stressors share a common conceptual denominator in that they reflect stimuli that are perceived by individuals as placing demands upon them and in that they correspond to the notion of chronic stressors as conceptualized by Lazarus (Lazarus, 1999) and by Wheaton (1999). Our comprehensive literature search on demand-based stressors reveals that only the above seven work stressors were those whose associations with job performance were found in at least four samples, which we determined as our minimum threshold to run a meta-analysis, to avoid reporting on chance results. Including these stressors in a meta-analysis is warranted because of the lack of clarity on how they may relate to performance. As we elaborate below, although all seven stressors are associated in one degree or another with hindrance at work, which may limit performance (see LePine, LePine, \& Jackson, 2004; LePine, Podsakoff, \& LePine, 2005), there are some important differences between them that may affect their relationships with performance.

Second, our approach to conceptually defining job performance was also comprehensive. Following past meta-analytical studies and the literature on the different facets of job performance, we covered all sources of performance ratings: self-rated performance, supervisor-rated performance, objective performance measures (e.g., sales volume), and general ratings of job performance (representing any combination of the above sources). We included the measure of general performance in our study to enable comparison of our findings with those reported with earlier metaanalytic inquiries that have used it. In addition, based on Viswesvaran, Ones, and Schmidt (1996), we examined two dimensions of performance: qualitative and quantitative, neither of which has hitherto been investigated 
meta-analytically. Following Viswesvaran et al. (1996) we have defined quality of performance as referring to any assessment of how well the job was done and quantity of performance as referring to ratings of quantity or volume of output that an individual has produced, both conceptualized irrespective of the source of the ratings. Qualitative and quantitative measures of performance were found, in a recent meta-analysis, to be only moderately meta-correlated (mean correlation $=.34$ ), but the $90 \%$ credibility value around this meta-correlation included zero, suggesting that it may be dependent upon situational factors (Viswesvaran, Schmidt, \& Ones, 1994). Overall, focusing on multiple measures of performance is important for the purpose of testing the convergent validity of our meta-analytic findings. Moreover, if the results would suggest consistency across all performance measures, it would alleviate concerns about the use of self-rated performance (e.g., self-bias or common method variance) or supervisorrated performance (e.g., inflated ratings of subordinates who are working in stressful conditions; cf. Westman \& Eden, 1991).

Third, we explored several moderators of the stressor-performance relationship, namely, organizational level and publication year, published versus unpublished studies, and types of measure used to assess specific stressors, none of which appear to have been examined in any prior metaanalysis of the stressor-performance relationship.

\section{The Relationship Between a Stressor and Job Performance}

Following the theoretical work of Lazarus and his colleagues (e.g., Lazarus \& Folkman, 1984), recent studies (for a review, see LePine et al., 2005) suggested that the appraisal of any stressor reflects two basic dimensions: The first dimension, associated with threat or hindrance, is hypothesized to be negatively associated with performance, and the second dimension, reflecting challenge, tends to be positively related to performance (see also Beehr, Jex, Stacy, \& Murray, 2000; Jex, 1998; McGrath, 1976).

The theoretical model that explains the expected negative relation between hindrance-based stressors and performance is the negative linear model, which postulates that stressors are detrimental to job performance (e.g., Allen, Hitt, \& Greer, 1982; Jamal, 1984, 1985; Kahn \& Byosiere, 1992). Several theoretical arguments are provided in the literature to support this type of stressor-performance linkage. First, when employees perceive a demand addressed to them as potentially threatening or eventually harmful, they will use up energy and time to cope with this stressor and with their immediate reactions to it (e.g., anxiety and discomfort). Therefore, work-related stressors are thought to reduce an employee's ability to perform by diverting effort away from performing job functions 
and toward coping with the stressors (Jex, 1998). Second, high levels of stressor are invariably associated with involuntary physiological responses that interfere with performance (Lazarus, 1999; Motowidlo, Packard, \& Manning, 1986). Third, these high levels of stressor tend to create conditions of information overload, which in turn may lead to a narrowing of individuals' perceptual attention so that they ignore performance-related information and cues, thus deleteriously affecting their job performance (Cohen, 1980). The theoretical model that explains the expected positive relation between challenge-based stressors and performance is the positive linear model, arguing that when a stressor is appraised primarily as a challenge it may lead to internal arousal and higher performance outcomes (LePine et al., 2005; McGrath, 1976).

\section{Differential Relationships of Role Stressors With Performance}

The two dimensions, threat or hindrance, and challenge were postulated to be reflected to a different extent in each of the stressors included in this study, leading us to expect that they would be differentially related to performance (cf. Drach-Zahavy \& Erez, 2002; LePine et al., 2005). This theoretical approach follows the cognitive-relational model of stress appraisal proposed by Lazarus and his colleagues (e.g., Lazarus \& Folkman, 1984; Lazarus, 1999), which posits that, relative to a situational demand, threat and challenge appraisals synergistically interact to produce stress appraisals. As pointed out by Folkman (Folkman, 1984), and as empirically verified in her research with Lazarus (cf. Folkman \& Lazarus, 1985), threat and challenge appraisals, a distinguished from one another by their cognitive components, are not mutually exclusive and can occur simultaneously with regard to a situational demand. Therefore, we postulate that, with regard to any type of situational demand under study, the higher the amount of perceived threat and the lower the amount of perceived challenge, the higher the resulting negative effect on individuals' job performance. Moreover, it is important to note that following the above theoretical contributions and accumulated evidence, which indicate that for each of the stressors under consideration one's overall assessment of its stressfulness combines threat and challenge appraisals, we would still expect its relation with performance to be negative. We base this argument on the well-established finding in social psychology that "bad is stronger than good" (Baumeister, Bratslavsky, Finkenauer, \& Vohs, 2001).

We hypothesized that role ambiguity would be the stressor most adversely related to performance at work. As originally conceptualized (Kahn, Wolfe, Quinn, Snoek, \& Rosenthal, 1964), role ambiguity refers to the relative unpredictability of the outcome of an individual's behavior. However, the most popular measure of role ambiguity also includes the 
component of lack of input from the environment to guide behavior (Rizzo, House, \& Lirtzman 1970, pp. 155-156). We argue that relative to the other stressors, role ambiguity is the least likely to have a challenge component because there are fewer coping processes that could possibly counteract its negative effects (King \& King, 1990). This argument is consistent with the argument of Kahn et al. (1964) that relative to other types of stressors, role ambiguity is more structurally determined. Therefore, when ambiguity is high, the individual faces the difficulty of pursuing job assignments because of an inability to modify them (cf., Lazarus \& Folkman, 1984). On the other hand, when role ambiguity is low (role clarity is high), employees' knowledge of what is expected of them (their job requirements) and how to achieve these expectations (processes and procedures) are high (Griffin, Neal, \& Parker, 2007; Murphy \& Jackson, 1999). This in turn facilitates a high level of job control, which is associated with higher job performance (Griffin et al., 2007). All previous meta-analytic reviews that covered role ambiguity supported our expectation of a relatively strong negative association between role ambiguity and performance (Fisher \& Gitelson, 1983; Jackson \& Schuler, 1985; Tubre \& Collins, 2000). Analogously, we expected situational constraints (a situation in which conditions in an employee's immediate work environment inhibit or constrain performance, like improper machinery or inadequate supplies) to follow role ambiguity as most adversely related to performance at work relative to all other stressors. Situational constraints represent a type of stressor likely to be detrimental to an individual's ability to function because the individual often has little control over these constraints (e.g., Jex, 1998; Peters \& O'Connor, 1980). The only past meta-analytic study (Villanova \& Roman, 1993) found only weak relationships between situational constraints and performance (in field studies, the corrected meta-correlation was -.05). Nevertheless, this finding could be due to the research limitations (e.g., only 5 years were covered in the literature search, as compared with 28 years covered by this study).

All other types of stressors included in our study, although primarily associated with hindrance at work, may to some degree also reflect a component of challenge and therefore were expected to have more complex relationships with performance. In the case of role conflict (which refers to a situation of conflict between focal individuals and different senders in the organization), people may negotiate with the different senders some priorities over task assignments, as well as the scheduling of delivery. Concerning role overload (which refers to a situation in which work demands exceed the available resources to meet them), it may have both negative and positive effects on performance. Conceivably, overload could be regarded as a threatening stressor with an adverse effect on performance because it imposes demands on the individual who does not have enough 
resources (e.g., time) to overcome them. However, role overload may also occur when high performers take on more tasks and responsibilities and therefore are motivated to perform them well. In this situation, role overload can be perceived as a challenge positively rather than negatively associated with performance (cf., LePine et al., 2005). Indeed, past studies have reported positive, negative, and no associations between overload and job performance (LePine et al., 2004; Spector \& Jex, 1998), possibly an indication that it may represent challenge and/or hindrance to the focal individuals. Similar to role overload, the relation of job insecurity and work-family conflict with performance may be complex. Thus, although job insecurity may lead to a reduction in effort and performance, associated with a reduced commitment to the organization, it can also lead to an increase in effort and performance. This may occur if the individual believes that higher performance will improve the organization's success and thus also the security of its employees, or if the individual believes that the organization's decision whom to keep versus whom to let go is contingent upon the contribution of each individual to the performance of the organization. Further, in the case of work-family conflict, it can be expected that this stressor, reflecting incompatible demands at work and home, would be negatively associated with performance (cf. Allen, Herst, Bruck, \& Sutton, 2000; Bronneberg, 1995; Yardley, 1995). However, individuals experiencing work-family conflict may feel compelled to keep their performance-related behavior at an acceptable level but may be less willing to engage in any work-related extra-role behavior, as suggested by past empirical research (Allen et al., 2000). Finally, uncertainty regarding the environment (environmental uncertainty) is often viewed as one of the defining features of life in organizations (Duncan, 1972; Ellis \& Shpielberg, 2003). However, because of its focus on threats in organizational environment, it represents a distal stressor relative to the other, more proximal stressors, and therefore, we expected it to have weaker linkages with performance relative to the other stressors. Our first hypothesis was therefore:

Hypothesis 1: Among the seven stressors studied in this metaanalysis, role ambiguity and situational constraints will be most strongly negatively related to job performance, relative to the other five stressors.

\section{Potential Moderators}

As already noted, all the stressor-performance reviews found a substantial amount of the variance in the corrected stressor-performance correlations that remained unexplained. Therefore, identifying the variables 
that moderate the stressor-performance relationship could contribute to our understanding of how stressors influence performance. A large number of potential moderators have been suggested in past qualitative and quantitative reviews of this research area, including age, education, gender, and seniority (e.g., Jex, 1998), but these moderators pose a theoretical challenge in their aggregate form. Several other potentially promising moderators, like climate of trust and involvement, have not been empirically addressed in a sufficient number of studies. In this study we examined the following moderators: job level, namely managers versus nonmanagers; year of publication of the study; published versus unpublished studies; and type of measure used to gauge role ambiguity and role conflict. In the following, we present the rationale for each moderator.

\section{Job Level}

Kahn et al. (1964) suggested that job level serves as a moderator of the relationship of role conflict and role ambiguity with various outcomes. However, the direction of this moderating effect is unclear. On the one hand, some researchers (see, Beehr \& Drexler, 1986; Hamner \& Tosi, 1974; Kahn et al., 1964) claimed that higher-level jobs tend to have more autonomy, decision latitude, and other coping resources (e.g., power, prestige, income) that enable individuals who occupy these jobs to better handle and cope with threatening work-related demands. These individuals also tend to have stronger internal coping resources, such as resiliency, which make it easier to effectively encounter stressful situations (Beehr \& Drexler, 1986). Therefore, expectedly, stressors-performance linkages would be weaker among managers as compared with nonmanagers. An alternative argument is that workers in managerial jobs often have more responsibility and obligations, and several past studies (cf. Schieman, Whitestone \& Van Gundy, 2006; Schuler, 1980) have shown that, relative to rank-and-file employees, they are more likely to feel "overworked" and to be exposed to a variety of work-related demands. This exposure, in turn, could be expected to lead to stronger stressors-performance linkages among managers relative to nonmanagers (e.g., Cohen, 1980; Szilagyi, 1977). Past meta-analytic studies have reported only limited support for the moderating effect of job level in the area of work stress (e.g., Fisher \& Gitelson, 1983; Jackson \& Schuler, 1985). We extended these early results by using job level, defined as managers versus nonmanagers, as a moderator across all stressors and categories of performance. Given the alternative rationales for the moderating effect of job level, and the inconsistent findings reported in the literature, we refrain from suggesting a formal hypothesis on the direction in which job level moderates the relation between job stress and performance. 


\section{Publication Year}

How does time of publication affect the relationship between work stressors and performance? There are alternative rationales that may lead to opposite predictions about the direction of this effect. On the one hand, studies over the years have become more rigorous methodologically, for example, by reducing common method variance, which could have artificially inflated past stressors-performance linkages. Also, some stressors, like role ambiguity, have become more prevalent; therefore, these would suggest a weaker relationship between work stressors and performance over time. On the other hand, the social information processing theory suggests that formally and informally conveyed information influences individuals' attitudes and behavior by directing their attention to certain stimuli (Salancik \& Pfeffer, 1978). Indeed, Barley and Knight (1992) attributed the rise in stress claims during the late 1980s to the increased coverage of stress-related news items in the media. This suggests that people have become more aware of the adverse effect of stress on their psychological, behavioral, and physiological reactions, and therefore, are also more comfortable in attributing poor performance to work-related stressors. Consequently, one would expect an increase in the negative relationship between role stress and work performance over time. Because of the conflicting alternative rationales for the direction of the effect of publication year, we refrain from providing a formal hypothesis.

\section{Published Versus Unpublished Studies}

Several researchers have raised the possibility that meta-analytic studies may produce inaccurate (e.g., upwardly biased) estimates of the relationships in question because of the publication bias, which reflects the premise that studies producing nonsignificant or unexpected results are less likely to be submitted and less likely to be accepted for publication (Hunter \& Schmidt, 1990). If such bias occurs, the resource of literature on the topic of interest becomes biased. Rosenthal and Rubin (1986) labeled this potential bias the "file drawer phenomenon," and Fried and Ager (1998) suggested that meta-analysts test for it by systematically comparing the results from published and unpublished studies. Following the above rationale, we expected that published studies would tend to report stronger negative correlations between stressors and job performance than unpublished studies, such as dissertations and unpublished conference papers. In this study we focused only on unpublished dissertations because of the 
difficulties we encountered in getting unpublished conference papers from the authors. Therefore we hypothesize:

Hypothesis 2: Published papers will report stronger negative correlations between stressors and job performance than unpublished dissertations.

\section{Measurement of Stressor}

The Rizzo et al. (1970) role conflict and role ambiguity scales have most often thus far measured these two types of stressors, and thus most past meta-analytical studies of stressor and performance reflect their psychometric characteristics. For example, Jackson and Schuler (1985) reported that $85 \%$ of the studies that they meta-analyzed had utilized the Rizzo et al. (1970) measures. There has been considerable criticism and debate in the occupational stress literature about the discriminant, convergent, and predictive validity of the Rizzo et al. (1970) measures (for references to the rich literature, see King \& King, 1990 and Netemeyer, Johnston, \& Burton, 1990). Tracy and Johnson (1981) in an analysis of the factor loadings of the Rizzo et al. scales found that subjects responded much more clearly to the stressor/comfort dimension than to the conflict/ambiguity dimension of the items. They concluded, therefore, that there is doubt regarding the meaning of each scale. King and King (1990, p. 62) went as far as to draw the following conclusion: "We firmly believe that partial responsibility for the inconsistencies in research findings about role conflict and ambiguity is due to deficiencies in measurement." This early work was followed up by Harris and Bladen (1994), who used CFA in analyzing a multitrait-multimethod matrix of the two types of stressors using different wording and examining their correlations with several criteria. They concluded that there is some wording effect on the two role stressor measures, but that even accounting for this source of method variance, at least some significant relationships remain (Harris \& Bladen, 1994). In this study, we compared the association of each of the role stressors relating to ambiguity and conflict with all performance variables separately for studies using the Rizzo et al. (1970) scales and studies using other scales to gauge the same role stressor. Based on the above rationale, we expected that:

Hypothesis 3: The effect sizes obtained for each of the two Rizzo et al. (1970) scales would be lower in magnitude than those obtained using other scales to gauge the same stressor. 


\section{Method}

\section{Identification and Selection of Studies}

We combined computer-based and manual search methods to locate as many studies as possible for this meta-analysis. The computerized databases we accessed to elicit relevant articles were PsycLIT, SocLIT, MEDLINE, ABI-INFO, Dissertation Abstracts International, and ERIC databases, covering the years 1975-2002. In examining these databases, we used key words identified on the basis of qualitative reviews (Wheaton, 1997, 1999), ${ }^{1}$ among them stressor, stress, hassles, environmental constraints, acute stressor or stress, and job performance. For each category, we searched for all possible types of specific stressors as key words. Altogether, we searched for more than 50 terms in each database. We then reviewed the bibliographies of all previous qualitative and quantitative reviews published on the subject of our research, and to double check for full coverage of all articles, we manually scanned all issues published since 1975 of 14 relevant journals: Academy of Management Journal; Anxiety; Stress and Coping; Human Performance; Human Relations; International Journal of Stress Management; Journal of Applied Psychology; Journal of Occupational Health Psychology; Journal of Organizational Behavior; Journal of Personal Selling and Sales Management; Journal of Vocational Behavior; Organizational Behavior and Human Decision Processes; Personnel Psychology; Stress Medicine; and Work and Stress.

The relevance of each primary study to our meta-analysis was determined based on how the authors conceptualized and measured the stressor and performance. We defined the population that we wished to generalize a priori as consisting of employed adults. Accordingly, job performance in primary studies needed to occur in a natural job setting and needed to be measured at the individual (as opposed to the group) level. Thus, laboratory studies and studies conducted in learning situations were excluded, as were studies done on students, patients, or other not gainfully employed participants. We included primary studies in which the stressor was assessed as perceived by employees, excluding studies that related to objective stressors like work hours. In addition, we excluded studies that did not report on sample size or that did not include effect sizes or statistics that could be converted to correlation coefficients. In addition,

\footnotetext{
${ }^{1}$ Based on reviews of the types of stressors in the field (Wheaton, 1997, 1999), we developed a long list of key words used in our searches of the literature. This list included the work-related hassles of noise, light, crowding, transportation, and temperature; the acute stressors of dismissal, layoff, violence, job change, and plant explosion; and-in addition to the chronic stressors represented in our study - under utilization of skills, underparticipation, lack of responsibility, interpersonal conflict, and anomie.
} 
when the same sample was used in two or more articles, we considered only the one that provided more information. However, if some variables were reported in one article but not in the other, we used the nonoverlapping data. Concerning the measurement of work-family conflict, we used the variables called work-family conflict or family-work conflict. When we had both in the same article, we combined them into one variable. In most cases, the studies we included in our meta-analysis assessed only work-family conflict. After applying these exclusion criteria, the analysis included a total of 169 independent samples encompassing 35,265 individuals. All in all, there were 374 effect sizes from 104 published studies and 33 unpublished doctoral dissertations. Specifically, there were 145 effect sizes for self-rated performance, 139 for supervisor-rated performance, 31 for objective ratings, 15 for qualitative performance, and 26 for quantitative performance, and 18 effect sizes were coded only as part of general performance because their measures or dimensions were not specified.

\section{Coding $^{2}$}

Variables such as sample size, all reliability indicators, effect size estimates, study source, and characteristics were thoroughly coded. Coding of the moderator variables was straightforward as most of them (e.g., the measure of stressor used, published vs. unpublished papers, publication year, and managers vs. nonmanagers) were clearly indicated in the studies. We coded organizational level as managers only when all study participants held supervisory or managerial positions and nonmanagers when none of the study participants held supervisory or managerial positions, thereby excluding all mixed samples. Moreover, when we coded role ambiguity we included only studies that assessed this construct directly; we did not include studies that reverse-coded positive role-clarity items. In addition, resource inadequacy was coded as a situational constraint (as in Villanova \& Roman, 1993).

Although peer ratings are frequently used in performance appraisals (Viswesvaran, Schmidt, \& Ones, 2002), we failed to find at least four samples that included correlations between any stressor and peer-rated performance and therefore did not include peer-rated performance in our study. Quality and quantity of performance was defined based on Viswesvaran et al. (1996) as "a measure of how well the job was done" and "ratings of the quantity or volume of work produced," respectively.

\footnotetext{
${ }^{2}$ For the sake of brevity and to reduce the overall size of this contribution, we did not append the list of meta-analyzed studies showing key-coded characteristics of each study. Interested readers are invited to request by e-mail a digital copy of this appendix.
} 
We should note that in many studies the sample size for a specific correlation was different from the overall sample size. Thus, in our metaanalysis we used the sample size that specifically related to the correlation in question. Moreover, in longitudinal studies, we coded the data available for both stressor and performance. If the data were available for several waves of measurement, we used those of the first wave. In field experiments, we used the data available for the pretest.

Primary studies often reported performance information from multiple sources, including objective assessment, supervisor ratings, and selfratings. To enable us to compare our findings to those of previous stressorperformance meta-analytical studies (such as Tubre \& Collins, 2000), in addition to coding each measure of performance, we also computed a general performance construct using the formula proposed by Rosenthal and Rubin (1986). If the primary study did not provide the correlations between the specific measures of performance employed, we used correlations provided by the most recent job performance meta-analysis (Conway \& Huffcutt, 1997). It is well established in the meta-analysis literature that correlations based on composites are more valid than correlations based on a single measure (Thoresen, Kaplan, Barsky, Warren, $\&$ de Chermont, 2003). In our study the composite measure of general performance takes into account the intercorrelations among the sourcespecific measures included in it (cf. Hunter \& Schmidt, 1990, p. 460). We used the Spearman-Brown prophecy formula (Hunter \& Schmidt, 1990, pp. 454-463) to compute the reliability of an equally weighted composite of general performance.

Accurate coding is crucial for a meta-analysis. Therefore, to enhance our confidence in the coding results, after all the 169 samples had been carefully coded, $15 \%$ of them were randomly selected and recoded by another coder in order to calculate interrater reliability, which in this study exceeded .90. Note that the interrater reliability coefficients were based on all quantitative information available in the coding sheets. In addition, in order to deal with deficient reporting in primary studies, we corresponded with several of the original investigators to obtain additional information.

\section{Meta-Analytical Procedures}

For the statistical analyses, we used the Comprehensive Meta-Analysis software (Borenstein \& Rothstein, 1999). We used the meta-analytical procedures of Hunter and Schmidt (2004) to correct observed correlations for sampling error and unreliability in measures of job stressors and job performance. Because some individual studies provided only partial information on these artifacts, the correlations were corrected following the optimal two-stage procedure recommended by Hunter and Schmidt 
(2004, pp. 173-175). In the first step, individually known artifacts were corrected. This produced a mean correlation corrected for the individually known artifacts and a variance corrected for those artifacts and for sampling error. The distributions of the artifacts available from the first step were then used to correct for the remaining artifacts (Hunter \& Schmidt, 2004, pp. 174-175). This practice is commonly followed in meta-analytic studies (for some cautions and reservations concerning this practice, see Hall \& Brannick, 2002).

To correct the various types of stressor and job performance measures for unreliability, we used the internal consistency reliabilities. In Table 1 we report the results of all measures and dimensions of performance using internal consistency estimates (when such estimates were reported). However, in the results section, we also report the correction for measurement error of performance as was suggested by Viswesvaran et al.(1996). Thus, we used Viswesvaran et al.'s meta-analytical estimates of interrater reliability of supervisor ratings (.52) to correct correlation of supervisor ratings. Because no sample reported the reliability of objective measures of performance, we assumed perfect reliability.

Confidence intervals and credibility intervals aid in providing the best estimate of the true nature of the relationship between two variables (Whitener, 1990) and the variability in the correlation. Accordingly, we report both the $95 \%$ confidence intervals and the $90 \%$ credibility intervals. Confidence intervals provide an estimate of the variability of the corrected mean correlation $(\rho)$ due to sampling error (Hunter \& Schmidt, 2004, p. 205). Credibility intervals provide information on the variability of the individual correlations across the samples examined. Credibility intervals are calculated by using the corrected standard deviation of $\rho$, referred to as $S D p$, and they provide information on whether moderators are likely to be present. Whitener (1990, p. 317) recommends that if the credibility interval is small and does not include zero, then the mean corrected effect size is probably the estimate of a single population parameter and moderators are not in operation. However, if the credibility interval is sufficiently large or includes zero, then $\rho$ probably represents the aggregate of several subpopulation means, each representing the operation of a significant moderator.

We calculated a homogeneity statistic $Q$ for each analysis. A significant $Q$ statistic supports the presence of moderators because it indicates that the residual variance is not homogenous (Hunter \& Schmidt, 2004). Scholars have other tests available to them for the same purpose, including the test of whether a credibility interval includes zero, which was described above, and also the $75 \%$ rule with respect to the variance attributable to artifacts. Though we considered other tests, we decided to give priority to the use of the $Q$ statistic because it provides the best balance between 


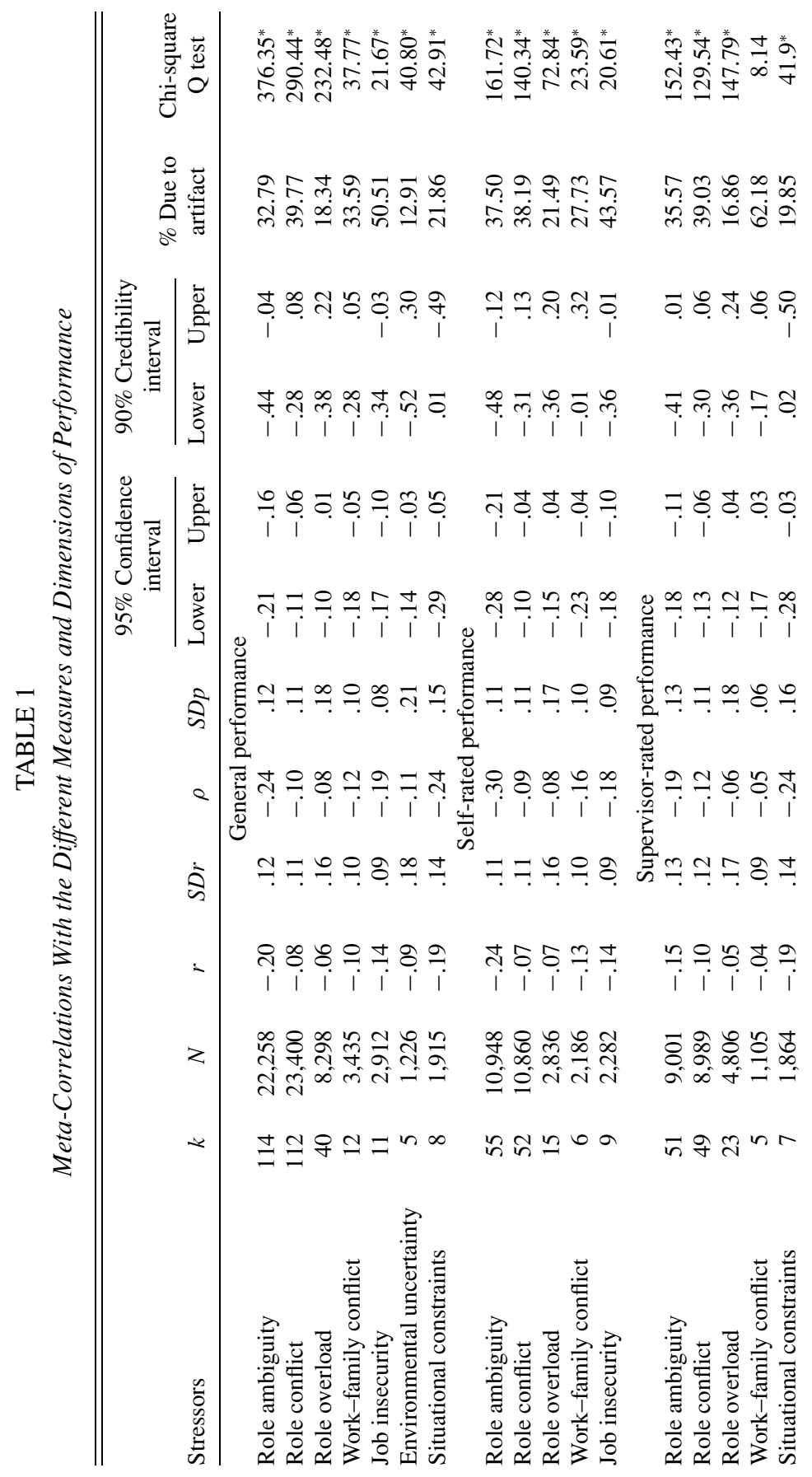




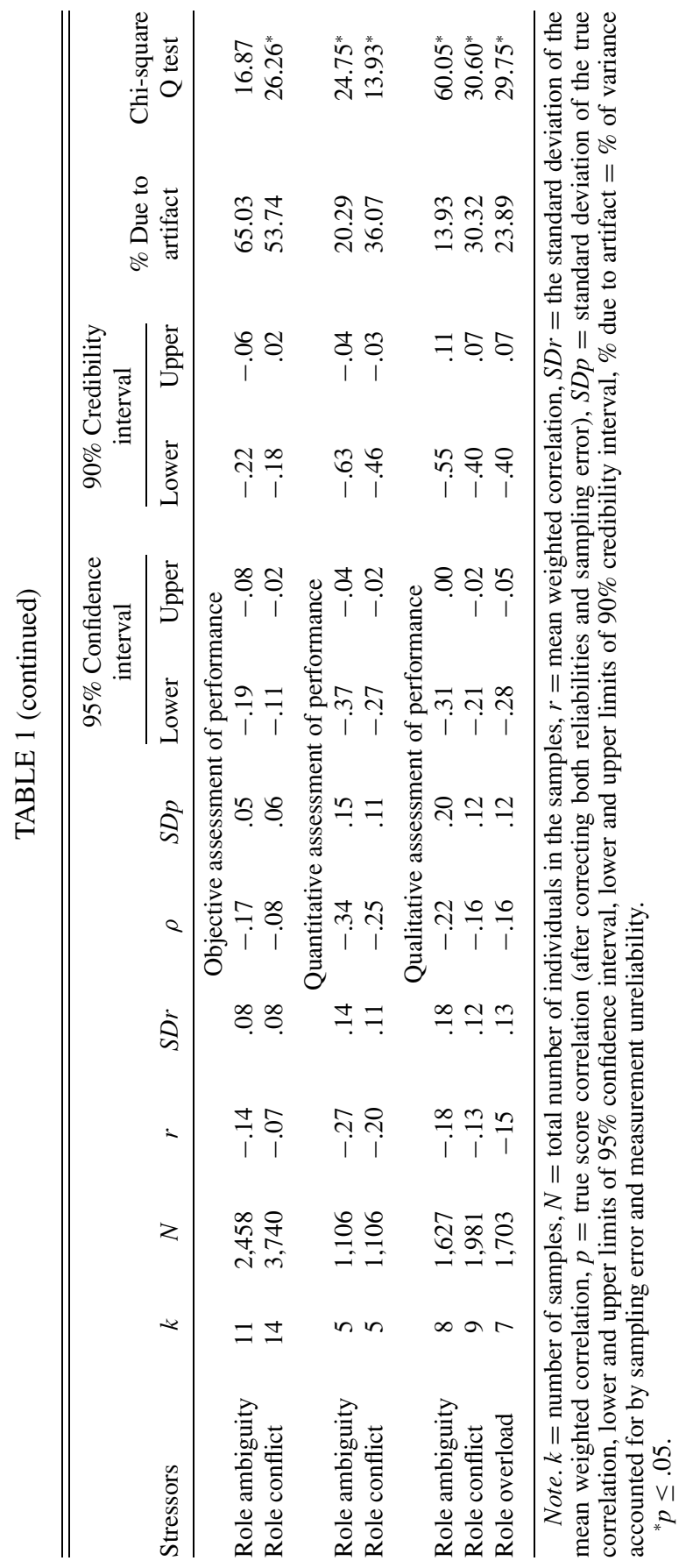


Type I error rates and statistical power (Cortina, 2003). When the $Q$ statistic indicated that moderators were probably present, we examined whether the effect sizes were different across the subgroups within each category: Any nonoverlapping of the confidence intervals of the subgroups can be interpreted as providing support for the moderation hypothesis. Yet another approach, applied in our study, was to examine the between-class effect $(Q b)$ : If the categorical moderator fully fits the data, the between-class effect $(Q b)$ is significant.

\section{Meta-Analytical Regression Analyses}

For testing the publication year moderating effect, we used metaanalytic regression analyses. We used weighted least squares (WLS; Neter, Wasserman, \& Kutner, 1989) to estimate the continuous moderators, following Steel and Kammeyer-Mueller (2002), who found it the most accurate method, and because the dependent variable in the regression analysis is heteroskedastic. The weights were set equal to $n j-3$ where $n j$ is the sample size in sample $j$.

\section{Results}

As already noted, a total of 374 effect sizes from 104 published studies and 33 unpublished doctoral dissertations were available for analysis. The samples ranged from 23 to 1,005 employees and the mean sample size across all the samples was 209 employees $(S D=157)$. Furthermore, the majority of samples reported data from organizations located within English-speaking countries (88\%). The response rate, reported in 100 studies, ranged from $15 \%$ to $100 \%$, with a mean of $66 \%(S D=20.5)$. The mean age of employees across the 72 samples in which age was reported was 36.5 years $(S D=6)$.

\section{Main Effects}

A summary of the overall relations between the various stressors and the different measures and dimensions of performance is presented in Table 1 . The data in the table include the number of studies investigating each relationship $(k)$, the total number of the individuals from these samples $(N)$, the mean weighted correlation $(r)$, the standard deviation of the mean weighted correlation $(S D r)$, the estimated true correlation (after correcting for both reliabilities and sampling error; $\rho$ ), the standard deviation of the estimated true correlation $(S D p)$, the lower and upper limits of the $95 \%$ confidence interval, the lower and upper limits of the $90 \%$ credibility interval, the percentage variance explained by artifacts, and the $Q$ test. 
Overall, the results supported Hypothesis 1. Specifically, as hypothesized, role ambiguity and situational constraints showed the highest correlations with performance. Role ambiguity's correlations with all the examined measures of performance were close or above -.20 , as follows: general performance $(\rho=-.24)$, self-rated performance $(\rho=-.30)$, supervisor-rated performance ( $\rho=-.19)$, objective assessment of performance $(\rho=-.17)$, quantitative assessment of performance $(\rho=-.34)$, and qualitative assessment of performance $(\rho=-.22)$. Similarly, situational constraints, which, because of insufficient data, were only examined in reference to general performance and supervisor-rated performance, showed a relatively high correlation $(\rho=-.24)$ with both of these performance criteria. As hypothesized, the other examined work stressors showed weaker correlations with the different performance criteria.

Role conflict's correlation with general performance, self-rated performance, and supervisor-rated performance ranged between $\rho=-.08$ and $\rho=-.12$. Only in the case of quantitative assessment of performance $(\rho=-.25)$ and qualitative assessment of performance $(\rho=-.16)$ were the correlations higher. Concerning the association between role overload and performance, we had data on general performance, self-rated performance, supervisor-rated performance, and qualitative assessment of performance. In the first three categories, role overload's association with performance was low (ranged between $\rho=-.06$ and $\rho=-.08$ ) and not significant. The only significant correlation was between role overload and qualitative assessment of performance $(\rho=-.16)$. Work-family conflict was modestly correlated with general performance $(\rho=-.12)$ and self-rated performance $(\rho=-.16)$. It also showed low and insignificant correlation with supervisor-rated performance $(\rho=-.05)$. Job insecurity showed moderate correlations with the two performance criteria we tested: general performance $(\rho=-.19)$ and self-rated performance $(\rho=-.18)$. Finally, environmental uncertainty was modestly correlated with general performance $(\rho=-.11)$. We also tested the first hypothesis using the Fisher $z$ transformation (Meng, Rosenthal, \& Rubin, 1992). Based on this test we found that for each of the performance measures, role ambiguity and situational constraints (when relevant) showed significantly higher correlations with the particular performance criterion than any of the other stressors $(p<.001)$. Finally, concerning supervisor-rated performance, Viswesvaran et al. (1996) argued that the appropriate correction for measurement error is that based on interrater reliabilities. Thus, Viswesvaran et al.'s meta-analytical estimates of interrater reliability of supervisor ratings (.52) were used to correct correlations of supervisor ratings, giving the following results: The corrected meta-correlations of role ambiguity and role conflict with supervisor-rated performance were $\rho=-.24$ (SD $\rho=$ $.16)$ and $\rho=-.15(S D \rho=.14)$, respectively. In addition, the estimated true 
correlations of role overload and work-family conflict with supervisorrated performance were $\rho=-.07(S D \rho=.24)$ and $\rho=-.07(S D \rho=$ $.08)$, respectively, and that of situational constraints with supervisor-rated performance was $\rho=-.29(S D \rho=.16)$. In sum, as hypothesized, role ambiguity and situational constraints were most strongly related to work performance, relative to the other work stressors.

\section{Potential Moderators}

Table 1 shows that for almost all meta-correlations the $Q$ tests of heterogeneity are significant, that the credibility interval is wide and includes zero even though most effect sizes were significantly different from zero, and that the proportions of variance accounted for by sampling error and measurement unreliability are far below $75 \%$. Thus, all three tests recommended in the literature (Hunter \& Schmidt, 2004) are in agreement, indicating that the correlations are not homogenous and suggesting the presence of moderators. There is variability in almost all the stressorperformance relationships examined after the variance attributed to artifacts is taken into account. In the following section, we report on the results of our tests for the existence of moderators.

\section{Job Level}

Table 2 depicts the results of the moderator analysis by job level. With the exception of role ambiguity, role conflict, and role overload, none of the other stressors met the requirement of at least four studies per subset. Overall, the results showed significant differences between managers and nonmanagers in four of the nine cases examined. These differences tend to suggest that the relationship of role overload with performance is stronger among managers than among nonmanagers. Specifically, role overloadgeneral performance effect size was significantly stronger among managers $(r=-.14)$ than among nonmanagers $(r=-.07)$. This pattern was also demonstrated in the relationship of both role overload $(r=-.12$ among managers and -.01 among nonmanagers) and role conflict ( $r=$ -.15 among managers and -.07 among nonmanagers) with self-rated performance.

\section{Publication Year}

In our regression analysis, we found that publication year had a significant negative effect on role ambiguity-general performance correlation $\left(\beta=-.20, \Delta R^{2}=.04, p=.04\right)$. However, the same effect in the case of role overload-general performance correlation was positive and significant 


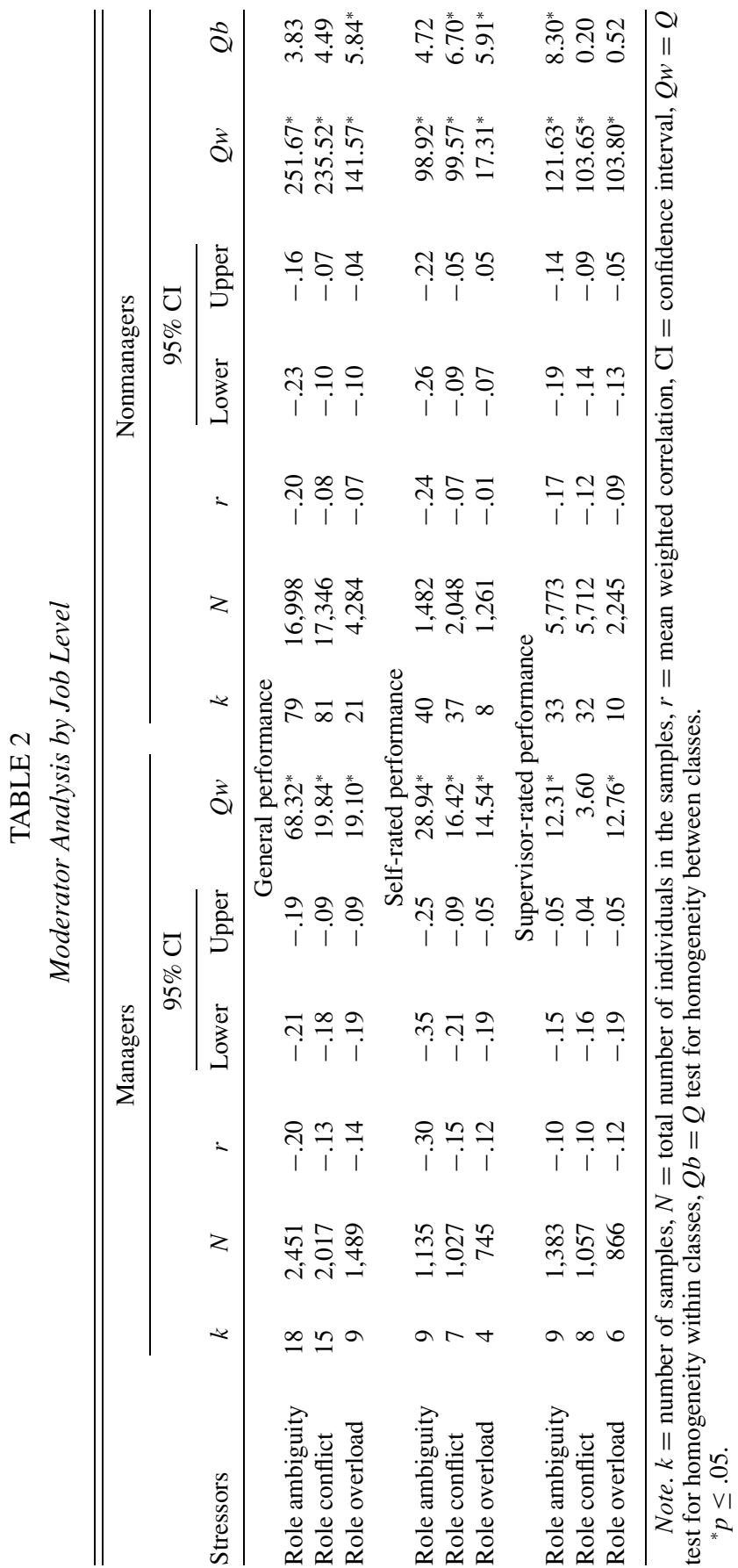


$\left(\beta=.40, \Delta R^{2}=.15, p=.01\right)$. The number of studies for the other stressors was insufficient to pursue an analysis on the effect of publication years.

\section{Published Versus Unpublished Studies}

As evident from Table 3, our results failed to support Hypothesis 2, which posited that published papers would report a stronger relationship between stressors and job performance than unpublished papers. In 6 of the 10 comparisons, the differences in the meta correlations between the two groups were not significant from each other. Moreover, the pattern of the observed differences between these correlations was not consistent. Of the remaining four comparisons, the correlations of role overload with general performance and self-rated performance in the published studies were significantly higher than the correlations between these variables in the unpublished dissertations. In contrast, role ambiguity showed significantly higher correlations with these two performance criteria based on the unpublished dissertations relative to the published studies. Therefore, we concluded that our second hypothesis was not supported.

\section{Rizzo et al. Scale Versus Other Scales}

The results described in Table 4 confirm that the type of stressor measurement used is a significant moderator. Both role ambiguity and role conflict had significantly lower correlations with performance when measured with the Rizzo et al. (1970) scale compared to all other scales, thus providing consistent support for our hypothesis in this regard. Moreover, these differences were also consistent along the different performance measures. For example, in the relationship between role ambiguity and general performance, studies using the Rizzo et al. scale had a significantly lower mean correlation $(r=-.18)$ than did those measuring role ambiguity with other scales $(r=-.23)$. Similarly, in the relationship between role conflict and general performance, studies using the Rizzo et al. scale had a significantly lower mean correlation $(r=-.06)$ than did those measuring role conflict with other scales $(r=-.17)$. Thus, it can be concluded that using the Rizzo et al. scale decreased the magnitude of both the role ambiguity and the role conflict correlations with the different performance measures compared to the other scales used.

Explorative Moderator Analyses

Following our finding that most of the effect sizes reported in Table 1 revealed heterogeneity across studies, indicating the need for moderator 


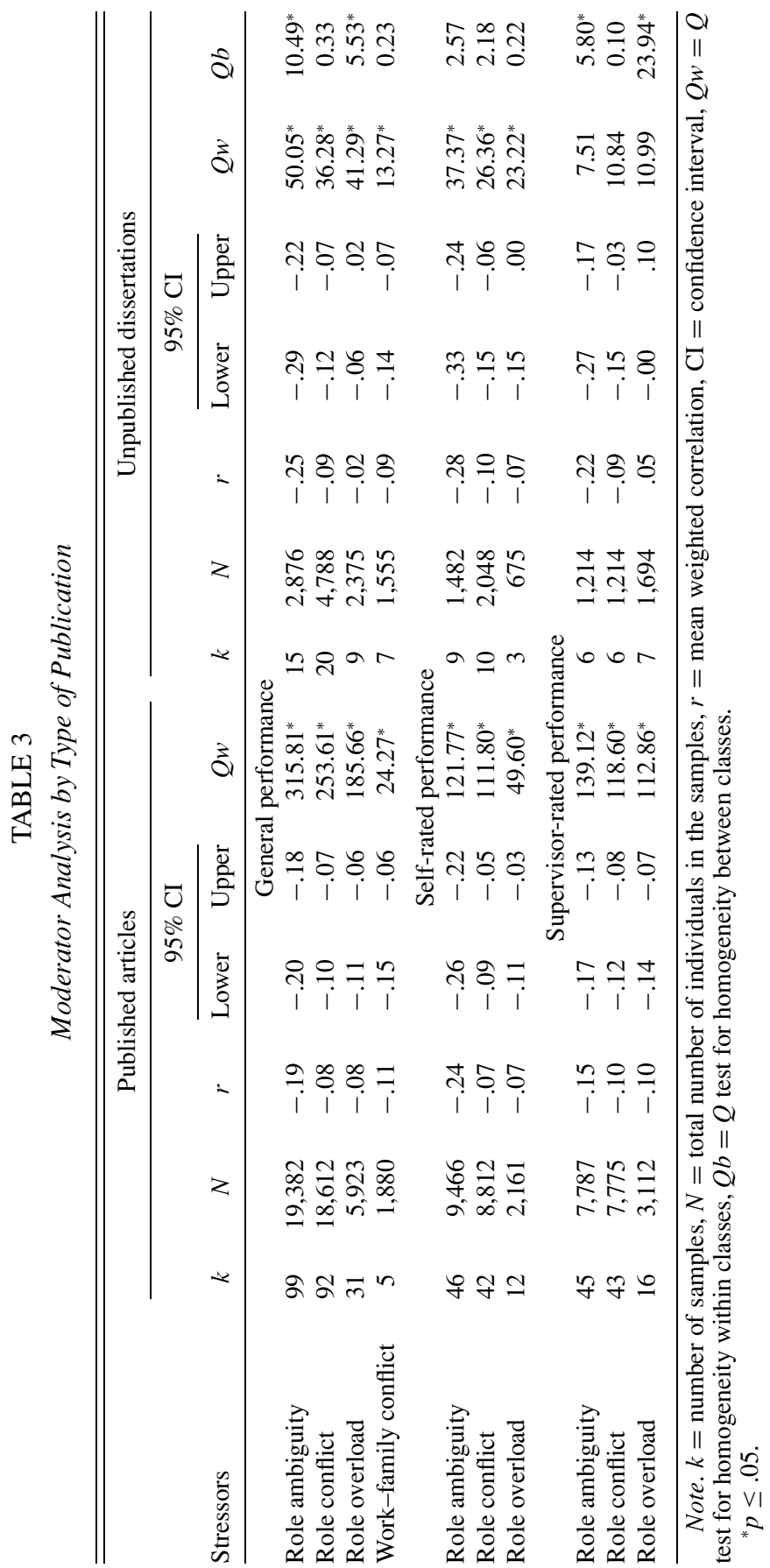




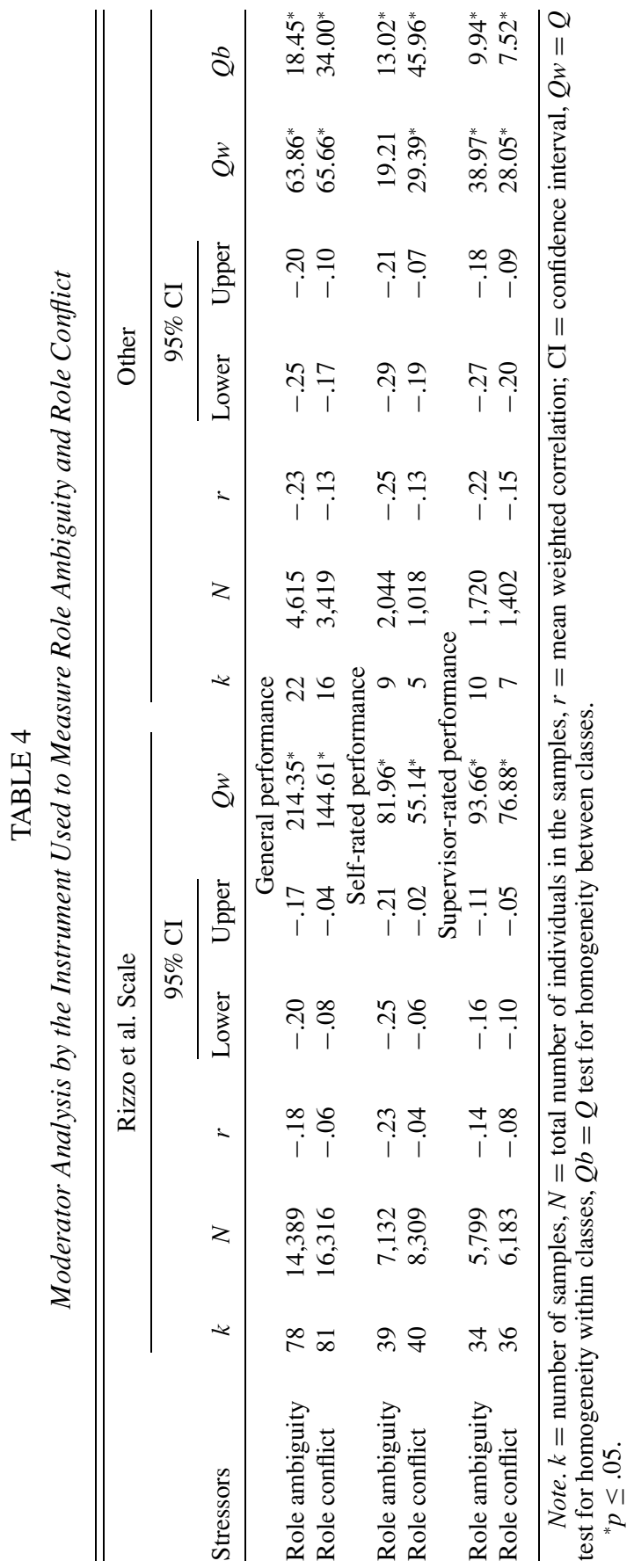


analyses, we conducted several explorative investigations of additional moderators, as reported below. We focused on moderators assessed as having the potential to contribute to future studies in this area.

English versus non-English speaking countries. As a general proxy for potential cross-cultural differences, effects were grouped by sample country origin into two categories: English-speaking countries versus all other countries. ${ }^{3}$ For role ambiguity, conflict, and overload relationships with the performance criteria we did not find evidence of a moderating effect of culture. For job insecurity there was a significant difference. Among the English-speaking countries, the relationships of job insecurity with both general performance and self-rated performance $(r=-.19$ and $r=-.22$, respectively) were double than those of the non-English speaking countries $(r=-.10$ for both general performance and self-rated performance).

Journal tier. We assessed the possible moderating effect of journal tier, expecting first-tier journals to show significantly higher effect sizes than second-tier journals. We culled the journals based on available prestige and impact ratings, defining as first tier the Academy of Management Journal, Administrative Science Quarterly, Journal of Applied Psychology, Journal of Health and Social Behavior, Journal of Organizational Behavior, Journal of Management, Journal of Personality and Social Psychology, Organizational Behavior and Human Decision Processes, Psychological Bulletin, and Personnel Psychology and as second tier all other journals. No consistent pattern was found for general performance or self-rated performance. However, the mean correlations of role ambiguity and role overload with supervisory-rated performance were significantly higher in the first-tier journals ( $r=-.15$ and -.16 , respectively) than the secondtier journals $(r=-.13$ and -.01 , respectively), thus, providing support for our expectations.

Predictor reliability. We also compared studies that provided information on predictor reliability with studies that did not include this information, with the idea that this might be a proxy variable reflecting the methodological rigor of the study (Dudley, Orvis, Lebiecki, \& Cortina, 2006). The results suggested that only studies providing information on role overload reliability demonstrated lower correlations as compared to studies that did not provide this information. ${ }^{4}$ We therefore concluded that our expectation was not confirmed.

\footnotetext{
${ }^{3}$ A copy of the table with the full set of results for this moderator is available by e-mail from the first and second authors. Interested readers should specify the name of the moderator.

${ }^{4}$ We are indebted to one of the anonymous reviewers of our manuscript for suggesting to us this idea.
} 
Controlling for stressor intercorrelations. Knowing of the intercorrelations among role ambiguity, conflict, and overload, and assuming that the meta-correlations of any one of them with job performance may change relative to those reported in Table 1 when the other two are controlled for, we computed semipartial correlations between all three role stressors and general job performance. That is, we computed the correlation between role ambiguity and job performance, with conflict and overload partialed out; the correlation between role conflict and job performance, with ambiguity and overload partialed out; and role overload and job performance, with ambiguity and conflict partialed out. We found that the negative correlation between role conflict and job performance turned positive but still significant when role ambiguity and role overload were partialed out, indicating that this relationship is somewhat influenced by the other role stressors. Role ambiguity, in turn, was significantly and negatively related to job performance even when the effects of role conflict and overload were partialed out. Finally, the relationship between role overload and job performance remained insignificant even when role ambiguity and role conflict were partialed out. ${ }^{4}$ In sum, these results indicated that the relationships of role ambiguity and role overload with performance are robust.

\section{Discussion}

\section{Summary of the Results}

Our study provided a comprehensive review of the relations among stressors and job performance. For the seven types of stressors covered by our study, and for all the measures and dimensions of performance considered, all stressor-performance relationships were consistently negative. The magnitude of the estimated true correlations varied across the seven stressors (from -.06 to -.34). Moreover, on the basis of the customary rule of a $95 \%$ confidence interval that did not include zero, 20 out of the 24 effect sizes were significant. A major contribution of our study is the finding that almost uniformly across all performance measures, role ambiguity, and situational constraints, meta correlations with them were higher relative to the meta correlations of the five other stressors considered. Moreover, role ambiguity maintained its negative relation with performance even when role conflict and role overload were partialed out. This finding is congruent with transactional stress theory (Lazarus \& Folkman, 1984), which regards role ambiguity as most detrimental to job performance. As suggested by a number of researchers (e.g., King \& King, 1990), employees' lack of knowledge of what is expected of them hampers and constricts any purposeful effort on their part to attain 
performance-related objectives. The high level of the negative relationship between situational constraints and performance was particularly striking. Jex (1998) postulated that "when organizational or job conditions make it more difficult for people to do their jobs, job performance would suffer" (p. 52). However, Villanova and Roman (1993) reported finding a very weak negative meta correlation of -.05 when they integrated past field research on this linkage. Hence, our study refines and extends their work, setting the record straight with respect to this stressor's relationships with performance.

Job insecurity, which is a growing threat in the globalized economy, was shown to have a modest negative association with job performance. Nevertheless, we also found some evidence to suggest that the effect of job insecurity may be moderated by context. Thus, in studies from Englishspeaking countries, the relationships of job insecurity with both general performance and self-rated performance were double that from studies from the non-English speaking countries. It may be that this difference in relationships between job insecurity and performance in English versus non-English speaking countries stems from the fact that non-English speaking countries (e.g., primarily European countries) tend to provide their citizens more safety nets if they lose their jobs compared to English speaking countries. It will be helpful for future research to examine this proposition based on more direct measures of cultural and societal differences.

The number of primary studies focusing on the expected negative relationship between work-family conflict and job performance has grown substantially, allowing us to assess associations of this stressor with the different measures of performance. Our results suggest that work-family conflict has detrimental effect on work performance. It was negatively correlated with both self-rated performance and general performance. Our finding in this regard adds credence to a recent meta-analytical review that underscored the potentially negative effects of work-family conflict on general job performance (Allen et al., 2000). Although in this meta-analysis we tripled the number of studies exploring work-family and performance, we obtained the same results as Allen et al. (2000) did regarding general performance, the only measure of performance used by Allen et al. However, it is interesting that the relation between work-family conflict and supervisor-rated performance was weak and not significant. This may suggest that employees are aware that supervisors are not likely to be sympathetic to deterioration in their performance because of family-related matters. Therefore, it could be that these employees would try to maintain or increase their supervisory ratings by selectively focusing in their energy expenditure on those job behaviors appraised by their supervisors. We clearly need more research to study under 
which contexts work-family conflict is more or less detrimental to work performance.

Of the four nonsignificant negative meta correlations obtained in our study (see Table 1), three concerned the stressor of role overload. As indicated in the introduction, it could be that in certain circumstances employees view role overload as a challenge, in this case it could be positively rather than negatively associated with job performance (LePine et al., 2005). In addition, role overload may consist of several dimensions, such as quantitative and qualitative role overload and job underload, that could be differentially related to performance (see French \& Caplan, 1978 and Sutherland \& Cooper, 2000).

Performance is a highly complex multidimensional construct, which can be measured in many ways. In this meta-analysis we examined for the first time quantitative and qualitative assessments of performance, which facilitated a more comprehensive understanding of the relationship between stressors and job performance. For example, we examined the relationships of role conflict and role ambiguity with quantitative and qualitative assessments of performance. The findings indicate a noticeably stronger relation between these two stressors and quantitative performance than qualitative performance, thus supporting the suggestion of Fried and Tiegs (1995) that future research on stressor-performance relationships could profit from assessing the relationships between stressors and specific dimensions of job performance.

\section{Moderators}

Our comprehensive meta-analysis generated new findings that concerned multiple moderators examined in our study. Our results indicated a stronger relationship of role conflict and role overload with performance for managers than nonmanagers. Future meta-analysis studies may benefit from exploring the difference in results between other professional and nonprofessional groups. We also found a positive effect of time of publication on the role ambiguity-general performance meta correlations, but a negative effect of time on role overload's correlations with general performance. This supports the importance of conducting future meta-analyses on the relation between work stressors and other outcomes to examine the moderating effect of publication year. In addition, similar to the results of other studies (Judge, Thoresen, Bono, \& Patton, 2001; Thoresen et al., 2003) our results were essentially similar for published and unpublished studies for almost all the relationships in question. However, we used only dissertations in the category of unpublished studies. Future studies would benefit from examining all sources of unpublished results (including, e.g., unpublished conference papers) when comparing the results between 
published and unpublished studies in the area of work stress and performance. Finally, consistent with other studies (MaGee, Ferguson, \& Seers, 1989), we found that the use of the Rizzo et al. (1970) scales significantly decreased the magnitude of both the role ambiguity and the role conflict correlations with the different performance measures, as compared to all other alternative scales of these stressors. This finding suggests that researchers who continue to use the Rizzo et al. (1970) scales will likely weaken their ability to explain performance.

\section{Reconciling Our Results With Previous Analytical Reviews}

This meta-analysis represents the most wide-ranging quantitative review of the association between work stressors and job performance. As noted in the introduction, for five of the seven stressors investigated here, namely, role ambiguity, role conflict, job insecurity, work-family conflict, and situational constraints, we updated and refined previous metaanalytical reviews. In this section, we highlight the communalities and divergences between our meta-analytical results and those of previous quantitative reviews, which focused on these stressors (Allen et al., 2000; Sverke, Hellgren, \& Naswall, 2002; Tubre \& Collins, 2000; Villanova \& Roman, 1993). Our results are not directly comparable with those of a recent meta-analytical inquiry by LePine et al. (2005) because their article reported only results based on the relationships of two clusters of work stressors to performance, clusters that were formed based on informed judges' assessments. Furthermore, LePine et al. (2005) consigned overload to one cluster and workload to the other without defining either.

The results of our study for the meta correlation of role ambiguity and general performance were similar to those of Tubre and Collins (2000), with $\rho=-.24,-.21$, respectively. In addition, our study and that of Tubre and Collins (2000) found comparable meta correlations of role ambiguity with self-rated performance, with $\rho=-.30,-.28$, respectively, and of role ambiguity with supervisor-rated performance, with $\rho=-.16,-.20$, respectively. The similarity could be related to the fairly large number of samples used in the two studies for these effect sizes. However, our study diverged from Tubre and Collins (2000) in the role ambiguity and objectively assessed performance meta-correlations, with $\rho=-.17,-.04$, respectively. A mirror image of this set of findings emerged when we compared our study with that of Tubre and Collins (2000) for the metacorrelations of role conflict with general, self-rated, supervisor-rated, and objectively assessed performance; the major divergence occurred with respect to the last-mentioned type of performance, with $\rho=-.08, .03$, respectively. This finding could be related to our basing our calculations 
on twice as many samples as Tubre and Collins (2000): 14, in comparison to 7 .

Sverke et al. (2002) reported a negative relationship between job insecurity and performance $(\rho=-.20)$ with a $95 \%$ confidence interval that included 0 , whereas using the same confidence interval, the negative meta correlation of $\rho=-.19$ found in this study was significant. A possible explanation for the relationship being significant in our study is that unlike Sverke et al. (2002) we decided to exclude articles that defined this stressor as satisfaction with job security (e.g., Stepina \& Perrewe, 1991; Yousef, 1998), regarding it as a strain or a reaction to the stressor, and therefore our standard error was substantively lower than that reported by Sverke et al. (2002). Our finding concerning situational constraints was not consistent with that of Villanova and Roman (1993), who quantitatively reviewed the relationship between situational constraints and performance in field studies. They found a negative weak relationship with general performance in field studies $(\rho=-.05)$, whereas in this study, the relationship of situational constraints and general performance was both significant and homogeneous $(\rho=-.24)$. Again, the different criterion for selecting the articles for inclusion is a potential explanation for this inconsistency. For example, Villanova and Roman (1993) included articles where the stressor was not subjectively reported by the study participants but was assessed by informed judges like district managers (Steel \& Mento, 1986; Steel, Mento \& Hendrix, 1987), but we excluded these studies because we focused on perceived stressors. We do not discuss in details the metaanalysis conducted by Spector and Jex (1998), because they used two or three samples to examine the relationships between job stressors and job performance (Spector \& Jex, 1998, p. 363). However, we should note that consistent with our findings, their scales of organizational constraints and interpersonal conflict had negative meta correlations $(-.11$ and -.10 , respectively) with supervisor-rated performance, whereas their scale of quantitative overload had a positive meta correlation with performance (.16).

The modest negative mean correlation of work-family conflict with self-rated performance $(\rho=-.16)$ and general performance $(\rho=-.12)$ augments and extends Allen et al. (2000) findings $(\rho=-12)$, which were based on only four samples and related only to general performance. However, the relation between work-family conflict and supervisor-rated performance was found to be insignificant. We have discussed this finding earlier in the discussion. In brief, we suggest that these weak results between work-family conflict and performance may reflect the lack of legitimacy in the work environment for work-family conflict to affect performance. We further argue the need for future studies to further explore this issue. 


\section{Theoretical Contributions and Future Research Directions}

From a theoretical perspective, these findings provide support for the model postulating that stressors are detrimental to job performance (Lazarus \& Folkman, 1984), thus concurring with earlier quantitative and qualitative reviews of the relationships between work stressors and variables often used as proxies of organizational effectiveness and productivity, including absenteeism (Johns, 1997), counterproductive behaviors (Lau, Au, \& Ho, 2003), accidents (Taylor \& Dorn, 2006), and turnover (Griffeth, Hom, \& Gaertner, 2000). However, our meta-analysis also provides evidence indicating that different stressors tend to have differential relationships with performance, and consequently, there is a need to further theorize and examine the causes for these differential relations. In our study we provided theoretical arguments in support of the differential relationships between different stressors and performance. However, there is a clear need for future research to further examine the circumstances, which contribute to the experience of stress, and the process by which employees combine and integrate threat and challenge appraisals in assessing a situational demand. Enhancing our understanding of the process of stress appraisal as combining and integrating challenge and hindrance appraisals would enable a more valid testing and a better understanding of the effect of a stressor on performance. For example, research should explore how the relative weight of perceived challenge versus threat in a given situation affects the individuals' experience of the situation as an opportunity or a threat. In addition, research would benefit from exploring the circumstances in which a situation is more likely to be perceived as a challenge or a threat. For example, role ambiguity may be perceived as a challenge in organizations that facilitate and reward involvement in new and challenging initiatives. In contrast, role ambiguity is more likely to be perceived as a threat in organizations that emphasize standardized operations and that reward performance based on the pursuit of well established processes and procedures. Individual differences, such as tolerance for ambiguity or need for clarity (Kahn et al., 1964), may also contribute to the experience of a challenge or a threat. Thus, individuals with high tolerance for ambiguity are more likely to perceive a potentially stressful situation as a challenge rather than a threat, compared to individuals with lower tolerance for ambiguity. Another example refers to role overload. It may be that role overload is perceived as more of a challenge when the organization is in a stage of growth and more of a threat when the organization is in a stage of decline.

Moreover, future research should also examine alternative avenues concerning the direction in which work stressors affect performance. One such avenue for future research to explore is the potential for curvilinear 
relations between the different role stressors and performance. It may be that for some stressors (e.g., role ambiguity) the strongest relation with performance is linear in nature. On the other hand, for other role stressors (e.g., role overload), the strongest relation with performance is curvilinear in nature. In the latter case, it may be that individuals who are motivated to be involved in multiple tasks perform well until the number of tasks or their difficulty exceeds the individuals' capabilities or resources. In addition, the fact that all statistical indicators $(Q$ test, credibility intervals, and proportions of variance accounted for by sampling error and measurement unreliability) support the presence of moderators should direct future research to systematically examine the effect of theoretically relevant moderators including those that we described in the introduction. One direction to follow may be to examine the interaction between and among different role stressors. As Fried, Ben-David, Tiegs, Avital, and Yeverechyahu (1998) proposed, it is possible that individuals are able to accommodate to one stressor at a time but will find it difficult to adjust and perform well in a situation in which two or more stressors are present at the same time. To test the possibility that stressors interact in affecting performance, researchers need to use individual-level data rather than the aggregated sample-level data used in this study.

Yet another direction for future research is to explore the effect of theoretically relevant moderators on the relations between particular role stressors and performance. For example, intolerance of ambiguity is a theoretically promising moderator of the stressor-performance relationship (Breaugh \& Colihan, 1994; Frone, 1990). Societal or organizational policies regarding treatment of unemployed individuals may be also used as moderators on the relationship between job insecurity and performance across different organizations and societies.

In addition, on the basis of available qualitative reviews in the literature (e.g., Bowers, Weaver, \& Morgan, 1996; Jex, 1998), future research might examine the moderating role of situational variables not considered in this study (Payne, 1991, provides a list of possible candidates). Specifically, the stressor-performance relationship can be moderated by job control, which was assessed as a moderator by large number of studies (see Spector, 1998). Additional moderators may be social support and organizational commitment, and the personality traits of self-esteem and locus of control (Jex, 1998, pp. 69-90).

Moreover, there is a paucity of research exploring the motivational, behavioral, cognitive, and physiological mechanisms (mediators) through which role stressors affect performance. Thus, there is a need to theoretically elaborate and empirically investigate the mechanisms linking stressors with job performance. For example, potential cognitive and physiological mediators may raise theoretical questions: Is it the energy and 
time expended by employees to cope with stressors or to deal with their negative affective reactions to stressors that account for the negative relationship? Does this mechanism also involve involuntary physiological responses to stressors that take their toll? Do these processes interact and, if so, in what fashion? Concerning motivational mediators, as Jex (1998) suggests, a stressor may affect performance by affecting antecedents of job performance such as the employee's commitment, motivation to invest effort, and motivation to maintain personal discipline. Emotional responses of employees to stressors such as emotional strain and job dissatisfaction may also serve as mediators (Fisher, 1980; Sullivan \& Bhagat, 1992), and so are behavioral responses, which may include absenteeism (Gupta \& Beehr, 1979), and involvement in work-related accidents that cause injury (Jones, 1990). Identifying specific variables that mediate the relationship between stressors and job performance could greatly improve our understanding of how stressors influence job performance.

Methodologically, our results provide evidence that support a cautious use of the stress measures of Rizzo et al. (1970) in primary stress research. Further, our results provide support for the utility of assessing the relationship between stressors and performance, based on self-report data (cf., Boomer, Johnson, Rich, Podaskoff, \& Mackenzie, 1995). Unlike any previous meta-analytic inquiry, our study enables a systematic comparison of the relations of several stressors across several performance dimensions. There are widely accepted concerns that individuals' self-rated performances may contribute to invalid conclusions on the relationship between role stress and performance. These concerns are based on two alternative arguments. The first argument is that self-report measures of both the independent (stressors) and dependent (self-rated performance) variables may inflate the correlation between the two because of common method variance. The alternative argument is that because self-rated performance is associated with self-enhancing tendencies that lead to overrated performance and lower variability in performance scores (Dunning, Heath, \& Suls, 2004), metacorrelations between self-rated performance and work stressors can be expected to be lower relative to objective or quantitative performance.

However, the results between the different role stressors and self-rated performance (as reported in Table 1) were for the most part similar or in the same direction to the results, which were based on supervisory ratings or objective performance data. This suggests that researchers and practitioners may obtain some useful information from self-report data on stress and performance.

Our findings have direct implications for the proponents of implicit stress theory who claim that the associations between supervisor-rated performance and stressors may be inflated due to the raters' beliefs that 
employees working under stressful conditions are likely to perform more poorly than those not exposed to work-related stressors (e.g., Perrewe, Fernandez, \& Morton, 1993; Westman \& Eden, 1991). Thus, for example, Westman and Eden (1991, p. 136) argued that only by measuring performance objectively, in a manner that precluded any coloring of performance by stressors, could we avoid the threat of implicit stress theory to the validity of other-rated performance. Our analysis failed to support the implicit stress theory: As we have indicated, the meta correlations of quantitative assessments of performance with role ambiguity and conflict, which are presumably less susceptible to the threat of implicit stress theory, yielded effect sizes almost twice the magnitude of those of the corresponding meta-correlations of these two stressors with supervisor-rated performance. Therefore, our findings do not undermine the concurrent validity of supervisory ratings of performance.

\section{Practical Implications and Limitations}

From a practical perspective, the increasing levels of work-related stressors in advanced market economies have underscored the need for researchers to understand the performance implications of stressors, to predict the effects of novel workplace stressors, and to devise interventions designed to reduce the potential negative effects of stressors on job performance. Our meta-analytical review provides initial guidance for responding to these research challenges. The results suggest that organizations should give priority to stressors such as role ambiguity and situational constraints. For example, managers can provide adequate employee training that alleviates situational constraints (Jex, 1998). Moreover, role ambiguity can be reduced by leaders' establishing clearer goals, expectations, and evaluation criteria. Similarly, organizations should alleviate organizational constraints by establishing supportive work environments in which employees are given the necessary tools, technology, and information to function effectively.

Our findings therefore strongly support organizational stakeholders' preventive stress management interventions designed to increase organizational effectiveness and productivity. Although a recent meta-analysis (Van der Klink, Blonk, Schene, \& van Dijk, 2001) found significant overall effects of stress-reducing interventions on strains and perceived quality of work life, the effects of stress interventions on individual performance and organizational effectiveness have hardly been investigated, partly because some managers adhere to implicit stress theories that relate stressors positively or curvilinearly to performance (Dewe \& O'Driscoll, 2002). Therefore, educators of future managers may find it practical to propagate findings such as ours whose major import is that organizational 
effectiveness and individual performance can be improved by endeavoring to reduce the stressors that employees perceive. Because the findings reveal relatively strong relationships of stressors with specific dimensions of performance, organizations may consider increasing the effectiveness of their performance appraisal systems by including in them several dimensions of performance like its quality and quantity. Constantly surveying the employees and learning which stressors are more prevalent and destructive to one's performance would enable organizations, together with their employees, to devise steps on how to minimize the adverse effects of these stressors on performance.

Like other meta-analyses, ours was based mostly on cross-sectional primary studies, which makes it impossible to assess the direction of causality (Deschamps, 1997; Spector, Dwyer \& Jex, 1988). Another caveat concerns the number of samples used in each calculation of effect sizes in this study. Caution should be exercised in drawing conclusions from estimates based on small numbers of samples (Oswald \& Johnson, 1998). Finally, it should be recognized that we limited our study to stressors, which are part of the category of work demands. Therefore, we did not study the effect of other variables such as job control (e.g., Stone, 1986), which are part of a broader category of work-related social-psychological stressors.

\section{REFERENCES}

References with an asterisk $\left(^{*}\right)$ indicate studies included in the meta-analysis.

Abramis DJ. (1994). Work role ambiguity, job satisfaction, and job performance: Metaanalysis and review. Psychological Reports, 75, 1411-1433.

Allen RD, Hitt MA, Greer CR. (1982). Occupational stress and perceived organizational effectiveness in formal groups: An examination of stressor level and stressor type. PERSONNEL PSYCHOLOGY, 35, 359-370.

Allen TD, Herst DEL, Bruck CS, Sutton M. (2000). Consequences associated with workto-family conflict: A review and agenda for future research. Journal of Occupational Health Psychology, 5(2), 278-308.

*Araghi MAK. (1981). The relationship between university faculty job satisfaction, role conflict, task clarity and productivity. Dissertation Abstracts International, 42(4), 1502A.

*Armstrong-Stassen M. (1993). Production workers' reactions to a plant closing: The role of transfer, stress, and support. Anxiety, Stress, and Coping, 6, 201-214

*Armstrong-Stassen M. (1994). Coping with transition: A study of layoff survivors. Journal of Organizational Behavior, 15, 597-621.

*Aryee S. (1992). Antecedents and outcomes of work-family conflict among married professional woman: Evidence from Singapore. Human Relations, 45, 813-837.

*Ashforth BE, Saks AM. (1996). Socialization tactics: Longitudinal effects on newcomer adjustment. Academy of Management Journal, 39, 149-179.

*Babakus E, Cravens DW, Johnston M, Moncrief WC. (1996). Examining the role of organizational variables in the salesperson job satisfaction model. The Journal of Personal Selling \& Sales Management, 16, 33-47. 
${ }^{*}$ Babakus E, Cravens DW, Johnston M, Moncrief WC. (1999). The role of emotional exhaustion in sales force attitude and behavior relationships. Journal of the Academy of Marketing Science, 27, 58-70.

*Babin BJ, Boles JS. (1998). Employee behavior in a service environment: A model and test of potential differences between men and women. Journal of Marketing, 62, 77-91.

*Bagozzi RP. (1978). Sales force performance and satisfaction as a function of individual difference, interpersonal, and situational factors. Journal of Marketing Research, 15, $517-531$.

Barley SR, Knight DB. (1992). Toward cultural theory of stress complaints. Research in Organizational Behavior, 14, 1-48.

${ }^{*}$ Bateman TS. (1980). A longitudinal investigation of role overload and its relationship with work behaviors and job satisfaction. Dissertation Abstracts International, 41(7), 3175A.

*Bauer TN, Green SG. (1994). Effect of newcomer involvement in work-related activities: A longitudinal study of socialization. Journal of Applied Psychology, 79, 211-223.

Baumeister RF, Bratslavsky E, Finkenauer C, Vohs KD. (2001). Bad is stronger than good. Review of General Psychology, 5(4), 323-370.

Beehr TA, Bhagat RS. (1985). Introduction to human stress and cognition in organizations. In Beehr TA, Bhagat RS (Eds.), Human stress and cognition in organizations (pp. 375-398). New York: John Wiley.

Beehr TA, Drexler JA. (1986). Social support, autonomy, and hierarchical level as moderators of the role characteristics-outcome relationships. Journal of Occupational Behaviour, 7, 207-214.

*Beehr TA, Jex SM, Stacy BA, Murray MA. (2000). Work stressors and coworker support as predictors of individual strain and job performance. Journal of Organizational Behavior, 21, 391-405.

*Behrman DN, Perreault WD. (1984). A role stress model of the performance and satisfaction of industrial salespersons. Journal of Marketing, 48, 9-21.

*Behrman DN, Bigoness WJ, Perreault WD. (1981). Sources of job related ambiguity and their consequences upon salespersons' job satisfaction and performance. Management Science, 27, 1246-1260.

*Bernardin HJ. (1979). The predictability of discrepancy measures of role constructs. PERSONNEL PSYCHOLOGY, 32, 139-153.

${ }^{*}$ Bertram DA, Hershey CO, Opila DA, Quirin O. (1990). A measure of physician mental work load in internal medicine ambulatory care clinics. Medical Care, 28, 458467.

*Bhagat RS. (1982). Conditions under which stronger job performance-job satisfaction relationships may be observed: A closer look at two situational contingencies. Academy of Management Journal, 25, 772-789.

*Boles JS. (1991). The effect of work and non-work influence upon the relationship between role stresses and selected work outcomes. Dissertation Abstracts International, 52(11), 4002A.

Bommer WH, Johnson JL, Rich GA, Podaskoff PM, Mackenzie SB. (1995). On the interchangeability of objective and subjective measures of employee performance: A meta-analysis. PERSONNEL PSYCHOLOGY, 48, 587-605.

Borenstein M, Rothstein H. (1999). Comprehensive meta-analysis. [Computer program]. Englewood, NJ: Biostat.

*Borucki Z (1987). Perceived organizational stress, emotions, and negative consequences of stress: Global self-esteem and sense of interpersonal competence as moderator variables. Polish Psychological Bulletin, 18, 139-148. 
Bowers CA, Weaver J, Morgan BB, Jr. (1996). Moderating the performance effects of stress. In Driskell JE, Salas E (Eds.), Stress and human performance (pp. 163-195). Mahwah, NJ: Erlbaum.

*Breaugh JA. (1980). A comparative investigation of three measures of role ambiguity. Journal of Applied Psychology, 65, 584-589.

Breaugh JA, Colihan JP. (1994). Measuring facets of job ambiguity: Construct validity evidence. Journal of Applied Psychology, 79, 191-202.

*Brief AP, Aldag RJ. (1976). Correlates of role indices. Journal of Applied Psychology, 61, 468-472.

Bronneberg EA. (1995). The interactive effects of psychological involvement and time spent on work-family conflict and the impact of work-family conflict on job performance. Dissertation Abstracts International, 56, 4566A.

*Brown SP, Leigh TW. (1996). A new look at psychological climate and its relationship to job involvement, effort, and performance. Journal of Applied Psychology, 81, $358-368$.

*Byosiere PHR. (1987). Effects of societal, organizational, and individual factors on job performance, job satisfaction, and job strain: Multiple structural equations modeling in a three wave longitudinal panel study of new teachers. Dissertation Abstracts International, 48(11), 2831A-2832A.

${ }^{*}$ Cagli U. (1985). A study of incongruence of role perceptions in sales forces. Dissertation Abstracts International, 47(1), 243A.

${ }^{*}$ Challagalla GN, Shervani TA. (1996). Dimensions and types of supervisory control: Effects on salesperson performance and satisfaction. Journal of Marketing, 60, 89-105.

${ }^{*}$ Chenhall RH, Brownell P. (1988). The effect of participative budgeting on satisfaction and performance: Role ambiguity as an intervening variable. Accounting Organizations and Society, 13, 225-233.

*Clayton SH. (1981). Moderators of the relationship between individual task structure congruencies and job satisfaction and performance. Dissertation Abstracts International, 42(3), 1235A.

Cohen S. (1980). After effects of stress on human performance and social behavior: A review of research and theory. Psychological Bulletin, 88, 82-108.

Conway JM, Huffcutt AI. (1997). Psychometric properties of multisource performance ratings: A meta-analysis of subordinates, peer, and self-ratings. Human Performance, $10,331-360$.

Cortina JM. (2003). Apples and oranges (and pears, oh my!): The search for moderators in meta-analysis. Organizational Research Methods, 6, 415-439.

*Cummings WT, Jackson DW, Ostrom LL. (1989). Examining product managers' job satisfaction and performance using selected organizational behavior variables. Journal of the Academy of Marketing Science, 17, 147-156.

*Darden WR, Hampton R, Howell RD. (1989). Career versus organizational commitment: Antecedents and consequences of retail salespeople's commitment. Journal of Retailing, 65, 80-106.

*Day DV, Bedeian AG. (1995). Personality similarity and work-related outcomes among African-American nursing personnel: A test of the supplementary model of personenvironment congruence. Journal of Vocational Behavior, 46, 55-70.

${ }^{*}$ Deluga RJ, Winters JJ. (1990). The impact of role ambiguity and conflict on resident assistants. Journal of College Student Development, 31, 230-236.

Deschamps JC. (1997). Attribution or explanations in everyday life. European Journal of Work and Organizational Psychology, 6, 7-24.

Dewe P, O'Driscoll M. (2002). Stress management interventions: What do managers actually do? Personnel Review, 31(1/2), 143-165. 
${ }^{*}$ Dougherty TW, Pritchard RD. (1985). The measurement of role variables: Exploratory examination of a new approach. Organizational Behavior and Human Decision Processes, 35, 141-155.

${ }^{*}$ Douthitt EA. (2001). Effects of leader behaviors on service employee role perceptions, fairness perceptions, and performance. Dissertation Abstracts International, 62(11), 3849A.

*Downey HK, Slocum JW. (1982). Managerial uncertainty and performance. Social Science Quarterly, 63, 195-207.

Drach-Zahavy A, Erez M. (2002). Challenge versus threat effects on the goal-performance relationship. Organizational Behavior and Human Decision Processes, 88(4), 667682.

*Dubinsky AJ. (1983). Psychological dimensions of the job: The case of customer contact personnel. Journal of Retail Banking, 5, 30-37.

*Dubinsky AJ, Hartley SW. (1986). Antecedents of retail salesperson performance: A pathanalytic perspective. Journal of Business Research, 14, 253-268.

${ }^{*}$ Dubinsky AJ, Hartley SW, Yammarino FJ. (1985). Boundary spanners and self-monitoring: An extended view. Psychological Reports, 57, 287-294.

*Dubinsky AJ, Michaels RE, Kotabe M, Lim CU, Moon H. (1992). Influence of role stress on industrial salespeople's work outcomes in the United States, Japan, and Korea. Journal of International Business Studies, first quarter, 23(1), 77-99.

${ }^{*}$ Dubinsky AJ, Mattson BE. (1979). Consequences of role conflict and ambiguity experienced by retail salespeople. Journal of Retailing, 55, 70-86.

${ }^{*}$ Dubinsky AJ, Yammarino FJ. (1984). Differential impact of role conflict and ambiguity on selected correlates: A two-sample test. Psychological Reports, 55, 699-707.

*Dubinsky AJ, Yammarino FJ, Jolson MA, Spangler WD. (1995). Transformational leadership: An initial investigation in sales management. Journal of Personal Selling \& Sales Management, 15, 17-31.

Dudley NM, Orvis KA, Lebiecki JE, Cortina JM. (2006). A meta-analytic investigation of conscientiousness in the prediction of job performance: Examining the intercorrelations and the incremental validity of narrow traits. Journal of Applied Psychology, $91,40-57$.

*Dunagen KJ, Uhl-bien M, Duchon D. (2002). LMX and subordinates performance the moderating effects of task characteristics. Journal of Business and Psychology, 17, $275-285$.

Duncan RB. (1972). Characteristics of organizational environments and perceived environmental uncertainty. Administrative Science Quarterly, 17(3), 313-327.

Dunning D, Heath C, Suls JM. (2004). Flawed self-assessment. Implications for health, education, and the workplace. Psychological Science in the Public Interest, 5(3), 69-106.

*Edwards GJ. (1985). The relationship between bureaucratic structure, autonomy, role ambiguity, job performance and job satisfaction for social workers. Dissertation Abstracts International, 46(7), 2072A.

Ellis S, Shpielberg N. (2003). Organizational learning mechanisms and managers' perceived uncertainty. Human Relations, 56(10), 1233-1254.

Fisher CD. (1980). On the dubious wisdom of expecting job satisfaction to correlate with performance. Academy of Management Review, 5, 607-612.

Fisher CD, Gitelson R. (1983). A meta-analysis of the correlates of role conflict and ambiguity. Journal of Applied Psychology, 68, 320-333.

*Flaherty TB, Dahlstrom R, Skinner SJ. (1999). Organizational values and role stress as determinants of customer-oriented selling performance. The Journal of Personal Selling \& Sales Management, 19, 1-18. 
Folkman S. (1984). Personnel control and stress and coping processes: A theoretical analysis. Journal of Personality \& Social Psychology, 46(4), 839-852.

Folkman S, Lazarus RS. (1985). It if changes it must be a process: Study of emotion and coping during three stages of college examination. Journal of Personality and Social Psychology, 48, 150-170.

*Fox ML, Dwyer DJ, Ganster DC. (1993). Effects of stressful job demands and control on physiological and attitudinal outcomes in a hospital setting. Academy of Management Journal, 36, 289-318.

French JRP, Caplan RD. (1978). Organizational stress and individual strain. In Organ DW (Ed.), The applied psychology of work behavior (pp. 307-340). Dallas, TX: Business Publications.

Fried Y, Ager J. (1998). Meta-analysis: Review, integration and recommendations: A guideline for meta-analysts. International Review of Industrial and Organizational Psychology, 13, 123-158.

Fried Y, Tiegs RB. (1995). Supervisors' role conflict and role ambiguity differential relations with performance ratings of subordinates and the moderating effect of screening ability. Journal of Applied Psychology, 80, 282-291.

*Fried Y, Ben-David HA, Tiegs RB, Avital N, Yeverechyahu U. (1998). The interactive effect of role conflict and role ambiguity on job performance. Journal of Occupational and Organizational Psychology, 71, 19-27.

Frone MR. (1990). Intolerance of ambiguity as a moderator of the occupational role stressstrain relationship: A meta-analysis. Journal of Organizational Behavior, 11, 309320.

*Frone MR, Yardley JK, Markley KS. (1997). Developing and testing an integrative model of the work-family interface. Journal of Vocational Behavior, 50, 145-167.

${ }^{*}$ Frost DE. (1983). Role perceptions and behavior of the immediate superior: Moderating effects of the prediction of leadership effectiveness. Organizational Behavior and Human Performance, 31, 123-142.

${ }^{*}$ Fulk J, Wendler E. (1982). Dimensionality of leader-subordinate interactions: A path-goal investigation. Organizational Behavior and Human Performance, 30, 241-264.

*Gerloff EA, Muir NK, Bodensteiner WD. (1991). Three components of perceived environmental uncertainty: An exploratory analysis of the effects of aggregation. Journal of Management, 17, 749-768.

${ }^{*}$ Goff SJ. (1990). The impact of a childcare center located at the work site on work/family conflict, absenteeism, and job performance. Dissertation Abstracts International, 50(9), 2976A.

*Grant-Vallone E. (1998). Work and family conflict: The importance of supportive work environments. Dissertation Abstracts International, 59(4), 1895B.

${ }^{*}$ Grant K, Cravens DW, Low GS, Moncrief WC. (2001). The role of satisfaction with territory design on the motivation, attitudes, and work outcomes of salespeople. Journal of the Academy of Marketing Science, 29, 165-178.

${ }^{*}$ Greenhaus JH, Bedeian AG, Mossholder KW. (1987). Work experiences, job performance, and feeling of personal and family well-being. Journal of Vocational Behavior, 31, 200-215.

Griffeth RW, Hom PW, Gaertner S. (2000). A meta-analysis of the antecedents and correlates of employee turnover: Update, moderator tests, and research implications for the millennium. Journal of Management, 26, 463-488.

Griffin MA, Neal A, Parker SK. (2007). The new model of work role performance: Positive behavior uncertain and interdependent contexts. Academy of Management Journal, $50,327-347$. 
Gupta N, Beehr TA. (1979). Job stress and employees' behavior. Organizational Behavior and Human Performance, 23, 373-387.

Hall SM, Brannick MT. (2002). Comparison of two random-effects methods of metaanalysis. Journal of Applied Psychology, 87(2), 377-389.

Hamner WC, Tosi HL. (1974). Relationships of role conflict and role ambiguity to job involvement measures. Journal of Applied Psychology, 59, 497-499.

*Hampton R, Dubinsky AJ, Skinner SJ. (1986). A model of sales supervisor leadership behavior and retail sales people's job-related outcomes. Journal of Academy of Marketing Science, 14, 33-43.

Harris MM, Bladen A. (1994). Wording effects in the measurement of role conflict and role ambiguity: A multitrait-multimethod analysis. Journal of Management, 20, 887-901.

${ }^{*}$ Hartenian LS, Hadaway FJ, Badovick GJ. (1994). Antecedents and consequences of role perceptions: A path analytic approach. Journal of Applied Business Research, 10, $40-50$.

${ }^{*}$ Hendrix WH, Steel RP, Leap TL, Summers TP. (1991). Development of a stress-related health promotion model: Antecedents and organizational effectiveness outcomes. Journal of Social Behavior and Personality, 6, 141-162.

*Hollon CJ. (1983). Machiavellianism and managerial work attitudes and perceptions. Psychological reports, 52, 432-434.

Hunter JE, Schmidt FL. (1990). Methods of meta-analysis. Newbury Park, CA: Sage.

Hunter JE, Schmidt FL. (2004). Methods of meta-analysis (2nd ed.). Thousand Oaks, CA: Sage.

*Hyatt TA. (1996). The effects of audit firm structure and auditors' locus of control on job stress, job satisfaction, and performance. Dissertation Abstracts International, 56(10), 4031A.

Jackson SE, Schuler RS. (1985). A meta-analysis and conceptual critique of research on role ambiguity and role conflict in work settings. Organizational Behavior and Human Decision Processes, 36, 16-78.

*Jamal M. (1984). Job stress and job performance controversy: An empirical assessment. Organizational Behavior and Human Performance, 33, 1-21.

*Jamal M. (1985). Relationship of job stress to job performance: A study of managers and blue-collar workers. Human Relations, 5, 409-424.

Jex SM. (1998). Stress and job performance: Theory, research, and implications for management practice. Thousand Oaks, CA: Sage.

Jex SM, Crossley CD. (2005). Organizational consequences. In Barling J, Kelloway EK, Frone MR (Eds.), Handbook of work stress (pp. 575-600). Thousand Oaks, CA: Sage.

${ }^{*}$ Johlke MC, Duhan DF. (2000). Supervisor communication practices and service employee job outcomes. Journal of Service Research, 3, 154-165.

*Johlke MC, Duhan DF, Howell RD, Wilkes RW. (2000). An integrated model of sales managers' communication practices. Journal of the Academy of Marketing Science, 28, 263-277.

*Johns M. (1994). Middle managers' perceived role changes and consequences in downsized organizations. Dissertation Abstracts International, 54(8), 4429B.

Johns G. (1997). Contemporary research on absence from work: Correlates, causes, and consequences. International Review of Industrial and Organizational Psychology, $12,115-174$.

*Johnson CD, Messe LA, Crano WD. (1984). Predicting job performance of low income workers: The work opinion questionnaire. PERSONNEL PSYCHOLOGY, 37, 291-299.

Jones JM. (1990). Stress at work takes costly toll. The APA Monitor, 21, 37. 
*Jones KC. (1992). Task specific self-concept in congruencies of the salesperson: An evaluation of their influence on role stress and job outcomes. Dissertation Abstracts International, 53(4), 1220A.

Judge TA, Thoresen CJ, Bono JE, Patton GK. (2001). The job satisfaction and job performance relationship: A qualitative and quantitative review. Psychological Bulletin, 127, 376-407.

Kahn RL, Byosiere P. (1992). Stress in organizations. In Dunnette MD, Hough LM (Eds.), Handbook of industrial and organizational psychology (2nd ed., Vol. 2, pp. 571650). Palo Alto, CA: Consulting Psychologists Press.

Kahn RL, Wolfe DM, Quinn RP, Snoek JD, Rosenthal RA. (1964). Organizational stress: Studies in role conflict and role ambiguity. New York: Wiley.

*Kimpel JMS. (1998). Effects of employer-sponsored work/family policies and programs on companies, careers and families. Dissertation Abstracts International, 59(4), 1349A.

King LA, King DW. (1990). Role conflict and role ambiguity: A critical assessment of construct validity. Psychological Bulletin, 107, 48-64.

*Klein HJ, Kim JS. (1998). A field study of the influence of situational constraints, leadermember exchange, and goal commitment on performance. Academy of Management Journal, 41, 88-95.

${ }^{*}$ Klein DJ, Verbeke W. (1999). Autonomic feedback in stressful environments: How do individual differences in autonomic feedback relate to burnout, job performance, and job attitudes in salespeople? Journal of Applied Psychology, 84, 911-924.

${ }^{*}$ Kossek EE, Colquitt JA, Noe RA. (2001). Care giving decision, well being, and performance: The effects of place and provider as a function of dependent type and work-family climates. Academy of Management Journal, 44, 29-44.

*Lagace RR. (1988). Role-stressor differences between salesmen and saleswomen: Effect on job satisfaction and performance. Psychological Reports, 62, 815-825.

*Latack JC. (1984). Career transitions within organizations: An exploratory study of work, nonwork, and coping strategies. Organizational Behavior and Human Performance, 34, 296-322.

Lau VCS, Au WT, Ho JMC. (2003). A qualitative and quantitative review of antecedents of counterproductive behavior in organizations. Journal of Business and Psychology, 18(1), 73-99.

Lazarus RS. (1993). From psychological stress to the emotions: A history of changing outlook. Annual Review of Psychology, 44, 1-21.

Lazarus RS. (1999). Stress and emotion. New York: Springer.

Lazarus RS, Folkman S. (1984). Stressor, appraisal, and coping. New York: Springer.

*Lee S, Lee W. (2001). Coping with job stress in industries: A cognitive approach. Human Factors and Ergonomics in Manufacturing, 11, 255-268.

LePine JA, LePine MA, Jackson CL. (2004). Challenge and hindrance stress: Relationships with exhaustion, motivation to learn, and learning performance. Journal of Applied Psychology, 89(5), 883-891.

LePine JA, Podsakoff NP, LePine MA. (2005). A meta-analytic test of the challenge stressorhindrance stressor framework: An explanation for inconsistent relationships among stressors and performance. Academy of Management Journal, 48(5), 764-775.

${ }^{*}$ Low GL, Carvens DW, Grant K, Moncrief WC. (2001). Antecedents and consequences of salesperson burnout. European Journal of Marketing, 35, 587-611.

*Lusch RF, Serpkenci RR. (1990). Personal differences, job tension, job outcomes, and store performance: A study of retail store managers. Journal of Marketing, 54, 85101.

*Lysonski S. (1985). A boundary theory investigation of the product manager's role. Journal of Marketing, 49, 26-40. 
*MacKenzie SB, Podsakoff PM, Ahearne M. (1998). Some possible antecedents and consequences of in-role and extra-role salesperson performance. Journal of Marketing, $62,87-98$.

MaGee GW, Ferguson CE, Seers A. (1989). Role conflict and role ambiguity: Do the scales measure these two constructs? Journal of Applied Psychology, 74, 815-818.

*Malone TL. (1990). The relationship between community college faculty job satisfaction and selected intrinsic and extrinsic factors. Dissertation Abstracts International, 50(12), 3864A.

${ }^{*}$ Margolin E. (1991). The effects of role conflict, role ambiguity, and locus of control on the perceptions of job performance among paraprofessionals in special education program in a New York City community school district. Dissertation Abstracts International, 52(4), 1288A.

${ }^{*}$ Marshalleck EF. (1997). The effect of education, job characteristics, and hospital unit structure on nurse performance and job satisfaction. Dissertation Abstracts International, 57(11), 6852B.

McGrath JE. (1976). Stress and behavior in organizations. In Dunnette MD (Ed.), Handbook of industrial and organizational psychology (pp. 1351-1395). Chicago: Rand McNally.

Meng X-L, Rosenthal R, Rubin DB. (1992). Comparing correlated correlation coefficients. Psychological Bulletin 111(1), 172-175.

*Michaels RE, Dixon AL. (1994). Sellers and buyers on the boundary: Potential moderators of role stressor-job outcome relationships. Journal of the Academy of Marketing Science, 22, 62-73.

*Miles RH. (1976). A comparison of the relative impacts of role perceptions of ambiguity and conflict by role. Academy of Management Journal, 19, 25-35.

${ }^{*}$ Miller RL, Griffin MA, Hart PM. (1999). Personality and organizational health: The role of Conscientiousness. Work \& Stress, 13, 7-19.

Motowidlo SJ, Packard JS, Manning MR. (1986). Occupational stress: Its causes and consequences for job performance. Journal of Applied Psychology, 71, 618-629.

Murphy PR, Jackson SE. (1999). Managing work-role performance. Challenges for the 21st century organizations and employees. In Ilgen DR, Pulakos ED (Eds.), The changing nature of work performance (pp. 325-365). San Francisco: Jossey-Bass.

Netemeyer R, Johnston M, Burton S. (1990). Analysis of role conflict and role ambiguity in a structural equations framework. Journal of Applied Psychology, 75, 148-157.

Neter J, Wasserman W, Kutner M. (1989). Applied linear regression models (2nd ed.). Homewood, IL: Irwin.

*Oldham GR, Kulik CT, Ambrose ML, Stepina LP, Brand JF. (1986). Relations between job facet comparisons and employee reactions. Organizational Behavior and Human Decision Processes, 38, $28-47$.

*Orpen C. (1982). The effect of social support on reactions to role ambiguity and conflict: A study among White and Black clerks in South Africa. Journal of Cross-Cultural Psychology, 13, 375-384.

* Orpen C, Bernath J. (1987). The effect of role conflict and role ambiguity on employee satisfaction and performance. Psychological Studies, 32, 25-28.

Oswald FL, Johnson JW. (1998). On the robustness, bias, and stability of statistics from meta-analysis of correlation coefficients: Some initial Monte Carlo findings. Journal of Applied Psychology, 83, 164-178.

*Parasuraman S, Alutto JA. (1984). Sources and outcomes of stress in organizational settings: Toward the development of a structural model. Academy of Management Journal, 27, 330-350. 
Payne R. (1991). Individual differences in cognition and the stress process. In Cooper CL, Payne R (Eds.), Personality and stress: Individual differences in the stress process (pp. 181-204). New York: John Wiley.

Perrewe PL, Fernandez DR, Morton KS. (1993). An experimental examination of implicit stress theory. Journal of Organizational Behavior, 14(5), 677-686.

Peters LH, O'Connor EJ. (1980). Situational characteristics and work outcomes: The influence of frequently overlooked construct. Academy of Management Review, 5(3), 391-397.

*Pierce JL, Gardner DG, Dunham RB, Cummings LL. (1993). Moderation by organizationbased self-esteem on role condition-employee response relationships. Academy of Management Journal, 36, 271-288.

*Piercy NF, Cravens DW, Lane N. (2001). Sales manager behavior control strategy and its consequences: The impact of gender differences. The Journal of Personal Selling \& Sales Management, 21, 39-49.

*Posner BZ, Randolph WA. (1980). Moderators of role stress among hospital personnel. Journal of Psychology, 105, 215-224.

${ }^{*}$ Rabinowitz S, Stumpf SA. (1987). Facets of role conflict, role-specific performance and organizational level within the academic career. Journal of Vocational Behavior, 30, $72-83$.

*Rahim MA. (1990). Moderating effects of hardiness and social support on the relationships of conflict and stress to job burnout and performance. In Rahim MA (Ed.), Theory and research in conflict management. New York: Praeger.

* Rahman A, Haque S. (1992). Perceived workload and performance of shift workers. Journal of Human Ergology, 21, 99-103.

*Reiber JU. (1999). Personality and coping as predictors of job outcomes in the work environment. Dissertation Abstracts International, 60(1), 400B.

${ }^{*}$ Rhoads GK, Singh J, Goodell PW. (1994). The multiple dimensions of role ambiguity and their impact upon psychological and behavioral outcomes of industrial salespeople. Journal of Personal Selling \& Sales Management, 14, 1-24.

Rizzo JR, House RJ, Lirtzman SI. (1970). Role conflict and role ambiguity in complex organizations. Administrative Science Quarterly, 15, 150-163.

*Roberts KL. (1984). An analysis of the relationship of principals' leadership style to teacher stress and job related outcomes. Dissertation Abstracts International, 44(7), 2002A.

*Roe RA, Zinovieva IL, Dienes E, Ten Horn LA. (2000). A comparison of work motivation in Bulgaria, Hungary and the Netherlands: Test of a model. Applied Psychology: An International Review, 49, 658-687.

*Roelens AI. (1983). Job stressor and burnout among staff nurses in acute-care hospitals. Dissertation Abstracts International, 44(2), 457B.

${ }^{*}$ Rogg KL. (1998). Organizational commitment in the post-loyalty area: Perceived organizational support, multiple commitments and other antecedents' effects on turnover intentions and job performance. Dissertation Abstracts International, 58(8), 4503B.

${ }^{*}$ Rosenblatt Z, Talmud I, Ruvio A. (1999). A gender-based framework of the experience of job insecurity and its effects on work attitudes. European Journal of Work and Organizational Psychology, 8, 297-217.

Rosenthal R, Rubin D. (1986). Meta-analytic procedures for combining studies with multiple effect sizes. Psychological Bulletin, 99, 400-406.

*Russ FA, McNeilly KM, Comer JM, Light TB. (1998). Exploring the impact of critical sales events. The Journal of Personal Selling \& Sales Management, 18, 1934. 
${ }^{*}$ Ruyter K, Wetzels M, Feinberg R. (2001). Role stress in call centers: Its effects on employee performance and satisfaction. Journal of Interactive Marketing, 15, 23-35.

*Saks AM, Ashforth BE. (2000). The role of dispositions, entry stressors, and behavioral plasticity theory in predicting newcomers' adjustment to work. Journal of Organizational Behavior, 21, 43-62.

Salancik GR, Pfeffer J. (1978). A social information processing approach to job attitudes and task design. Administrative Science Quarterly, 23(2), 224-253.

${ }^{*}$ Salyer J. (1993). The effects of environmental turbulence on nurse performance. Dissertation Abstracts International, 54(4), 1893B.

${ }^{*}$ Sargent LD, Terry DJ. (1998). The effects of work control and job demands on employee adjustment and work performance. Journal of Occupational and Organizational Psychology, 71, 219-236.

${ }^{*}$ Schaubroeck J, Fink LS. (1998). Facilitating and inhibiting effects of job control and social support on stress outcomes and role behavior: A contingency model. Journal of Organizational Behavior, 19, 167-195.

Schaufeli WB, Enzmann D. (1998). The burnout companion to study and practice: A critical analysis. Washington, DC: Taylor \& Francis.

Schieman S, Whitestone YK, Van Gundy K. (2006). The nature of work and the stress of higher status. Journal of Health and Social Behavior, 47(3), 242-257.

${ }^{*}$ Schmieder RA. (1995). Construct validity of worker control and assessment of an expanded job demands control model. Dissertation Abstracts International, 56(4), 2367B.

${ }^{*}$ Schoob C. (2001). Personality and job performance under non-routine conditions. Dissertation Abstracts International, 61(11), 6173B.

Schuler RS. (1980). Definition and conceptualization of stress in organizations. Organizational Behavior and Human Performance, 25, 184-215.

${ }^{*}$ Schuler RS, Aldag RJ, Brief AP. (1977). Role conflict and ambiguity: A scale analysis. Organizational Behavior and Human Performance, 20, 111-128.

*Schweiger DM, Desi AS. (1991). Communication with employees following a merger: A longitudinal field experiment. Academy of Management Journal, 34, 110135.

${ }^{*}$ Sebolsky-Rubenstein JR. (2002). Participative decision making (PDM) and performance: An examination of possible mediating processes. Dissertation Abstracts International, 63(3), 1599B.

${ }^{*}$ Seybolt JW, Pavett CM. (1979). The prediction of effort and performance among hospital professionals: Moderating effects of feedback on expectancy theory formulations. Journal of Occupational Psychology, 52, 91-105.

*Singh J. (1998). Striking a balance in boundary-spanning positions: An investigation of some unconventional influences of role stressors on job characteristics on job outcome of salespeople. Journal of Marketing, 62, 69-86.

*Singh J, Goolsby JR, Rhoads GK. (1994). Behavioral and psychological consequences of boundary spanning burnout for customer service representatives. Journal of Marketing Research, 31, 558-569.

*Skyrme PYT. (1992). The relationship of job stressors to work performance, intent to quit, and absenteeism of first line supervisors. Dissertation Abstracts International, 53(4), 2093B.

*Sohi RS, Smith DC, Ford NM. (1996). How does sharing a sales force between multiple divisions affect salespeople? Journal of the Academy of Marketing Science, 24, 195-207.

*Somers MJ. (2001). Thinking differently: Assessing nonlinearities in the relationship between work attitudes and job performance using a Bayesian neural network. Journal of Occupational and Organizational Psychology, 74, 47-61. 
Spector PE. (1998). A control theory of the job stress process. In Cooper CL (Ed.), Theories of organizational stress (pp. 153-169). Oxford, UK: Oxford University Press.

*Spector PE, Dwyer DJ, Jex SM. (1988). Relation of job stressors to affective, health, and performance outcomes: A comparison of multiple data sources. Journal of Applied Psychology, 73, 11-19.

Spector, P.E., \& Jex, S.M. (1998). Development of four self-report measures of job stressors and strain: Interpersonal conflict at work scale, organizational constraints scale, quantitative workload inventory, and physical symptoms inventory. Journal of Occupational Health Psychology 3(4), 356-367.

*Spreitzer GM. (1995). An empirical test of a comprehensive model of interpersonal empowerment in the workplace. American Journal of Community Psychology, 23, 601629.

*Srivastava AK. (1991). Moderating effect of mode of coping on the relationship between occupational stress and performance. Journal of the Indian Academy of Applied Psychology, 17, 93-98.

*Srivastava AK., Krishna A. (1991). A test of inverted "U"-hypothesis of stress-performance relationship in the industrial context. Psychological Studies, 36, 34-38.

Steel PD, Kammeyer-Mueller JD. (2002). Comparing meta-analytic moderator estimation techniques under realistic conditions. Journal of Applied Psychology, 87, 96111.

Steel RP, Mento AJ. (1986). Impact of situational constraints on subjective and objective criteria of managerial job performance. Organizational Behavior and Human Decision Processes, 37, 254-265.

Steel RP, Mento AJ, Hendrix WH. (1987). Constraining forces and the work performance of finance company cashiers. Journal of Management, 13, 473-482.

Stepina LP, Perrewe PL. (1991). The stability of comparative referent choice and feelings of inequity: A longitudinal field study. Journal of Organizational Behavior, 12, 185-200.

Stone EF. (1986). Job scope-job satisfaction and job scope-job performance relationships. In Locke EA (Ed.), Generalizing from laboratory to field settings. Lexington, MA: Lexington Books.

*Stumpf SA, Rabinowitz S. (1981). Career stage as a moderator of performance relationships with facets of job satisfaction and role perceptions. Journal of Vocational Behavior, $18,202-218$.

Sullivan SE, Bhagat RS. (1992). Organizational stress, job satisfaction and job performance: Where do we go from here? Journal of Management, 18, 353-374.

Sutherland V, Cooper CL. (2000). Strategic stressor management. London: Macmillan.

Sverke M, Hellgren J, Naswall K. (2002). No security: A meta-analysis and review of job insecurity and its consequences. Journal of Occupational Health Psychology, 7 , 242-264.

*Szilagyi AD. (1977). An empirical test of causal inference between role perceptions, satisfaction with work, performance and organizational level. PERSONNEL PSYCHOLOGY, 30, 375-388.

*Szilagyi AD, Sims HP, Keller RT. (1976). Role dynamics, locus of control and employee attitudes and behavior. Academy of Management Journal, 19, 259-276.

*Tanner JF. (1990). Vertical exchange quality and performance: Studying the role of the sales manager. Journal of Personal Selling \& Sales Management, 10, 17-27.

Taylor AH, Dorn L. (2006). Stress, fatigue, and risk of road accidents among professional drivers: The contribution of physical inactivity. Annual Review of Public Health, 27, 371-391. 
*Thoresen CJ. (2001). Antecedents and consequences of coping with setbacks at work: A theory-driven framework. Dissertation Abstracts International, 61(8), 4461B.

Thoresen CJ, Kaplan SA, Barsky AP, Warren CR, de Chermont K. (2003). The affective underpinnings of job perceptions and attitudes: A meta-analytic review and integration. Psychological Bulletin, 129, 914-945.

${ }^{*}$ Tivendell J, Bourbonnais C. (2000). Job insecurity in a Canadian civil servant as a function of personality and perceived job characteristics. Psychological Reports, 87, 55-60.

Tracy L, Johnson TW. (1981). What do the role conflict and role ambiguity scales measure? Journal of Applied Psychology, 66, 464-469.

${ }^{*}$ Troving JA. (1987). Conflict between teaching and research among university professors. Dissertation Abstracts International, 48(1), 102A.

*Tsui AS, O'Reilly CA. (1989). Beyond simple demographic effects: The importance of relational demography in superior-subordinate dyads. Academy of Management Journal, 32, 402-423.

Tubre TC, Collins JM. (2000). Jackson and Schuler (1985) revisited: A meta-analysis of the relationships between role ambiguity, role conflict and job performance. Journal of Management, 26, 155-169.

*Turner JH. (1999). Consequences of contingent compensation. Dissertation Abstracts International, 60(6), 2129A.

Van Der Klink J, Blonk R, Schene A, van Dijk FJH. (2001). The benefits of interventions for work-related stress. American Journal of Public Health, 91(1), 391-410.

*Venkatachalam M. (1995). Personal hardiness and perceived organizational support as links in the role stress-outcome relationship: A person-environment model. Dissertation Abstracts International, 56(6), 2328A.

*Viator RE. (2001). The association of formal and informal public accounting mentoring with role stress and related job outcomes. Accounting, Organizations and Society, 26, 73-93.

Villanova P, Roman MA. (1993). A meta-analytic review of situational constraints and workrelated outcomes: Alternative approaches to conceptualization. Human Resource Management Review, 3, 147-175.

Viswesvaran C, Ones DS, Schmidt FL. (1996). Comparative analysis of the reliability of job performance ratings. Journal of Applied Psychology, 81, 557-574.

Viswesvaran C, Schmidt FL, Ones DS. (1994). Quality and quantity in job performance: A meta-analysis. Paper presented at the 23rd International Conference of Applied Psychology, Madrid, Spain.

Viswesvaran C, Schmidt FL, Ones DS. (2002). The moderating influence of job performance dimensions on convergence of supervisory and peer ratings of job performance: Unconfounding construct-level convergence and rating difficulty. Journal of Applied Psychology, 87, 345-354.

*Von Emster GR, Harrison AA. (1998). Role ambiguity, spheres of control, burnout, and work-related attitudes to teleservice professionals. Journal of Social Behavior and Personality, 13, 375-385.

*Vroom PI. (1992). Role conflict, commitment, and coping, and scholarly productivity and satisfaction of social work academics. Dissertation Abstracts International, 52(7), 2433A.

*Ward MD. (1996). The impact of an individual's preparation for work on work values, work beliefs and initial work outcomes. Dissertation Abstracts International, 57(4), 1738A.

Westman M, Eden D. (1991). Implicit stress theory: The spurious effects of stress on performance ratings. Journal of Social Behavior and Personality, 6(1), 127-140. 
Wheaton B. (1997). The nature of chronic stress. In Gottlieb BH (Ed.), Coping with chronic stress (pp. 43-73). New York: Plenum Press.

Wheaton B. (1999). The nature of stressors. In Horwitz AV, Scheid TL (Eds.), A handbook for the study of mental health: Social contexts, theories, and systems (pp. 176-197). New York: Cambridge University Press.

Whitener EM. (1990). Confusion of confidence intervals and credibility intervals in metaanalysis. Journal of Applied Psychology, 75, 315-321.

*Williams ML, Podsakoff PM, Huber V. (1992). Effects of group-level and individual-level variation in leader behaviors on subordinate attitudes and performance. Journal of Occupational and Organizational Psychology, 65, 115-129.

*Yardley JK. (1995). The relationships of work-family conflict with work outcomes: A test of a model. Dissertation Abstracts International, 55(11), 5113B.

Yousef DA. (1998). Satisfaction with job security as a predictor of organizational commitment and job performance in a multicultural environment. International Journal of Manpower, 19, 184-194.

*Zahra SA. (1985). A comparative study of the effect of role ambiguity and conflict on employee attitudes and performance. Akron Business and Economic Review, 16, $37-43$. 